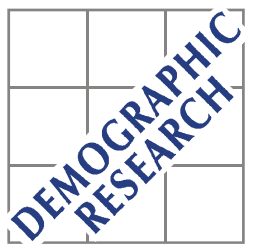

Demographic Research a free, expedited, online journal of peer-reviewed research and commentary in the population sciences published by the Max Planck Institute for Demographic Research Doberaner Strasse 114 D D-18057 Rostock · GERMANY www.demographic-research.org

DEMOGRAPHIC RESEARCH

VOLUME 5, ARTICLE 5, PAGES 125-186

PUBLISHED 28 NOVEMBER 2001

www.demographic-research.org/Volumes/Vol5/5/

DOI: $10.4054 /$ DemRes.2001.5.5

\title{
Cohort reproductive patterns in the Nordic countries
}

Tomas Frejka

Gérard Calot

(C) 2001 Max-Planck-Gesellschaft. 


\section{Table of Contents}

1 Introduction 126

2 General features of the social and economic $\quad 127$ environment in the Nordic countries

3 Cohort fertility in the Nordic countries 128

$4 \quad$ Public policies and fertility in the Nordic countries 136

$\begin{array}{lll}5 & \text { Achieving desired goals } & 137\end{array}$

$\begin{array}{lll}6 & \text { Concluding remarks } & 139\end{array}$

$\begin{array}{ll}\text { Notes } & 140\end{array}$

$\begin{array}{ll}\text { References } & 141\end{array}$

A.1 Appendix 1. Denmark 143

A.2 Appendix 2. Finland 153

A.3 Appendix 3. Norway 168

$\begin{array}{lll}\text { A.4 Appendix 4. Sweden } & 178\end{array}$ 


\title{
Cohort reproductive patterns in the Nordic countries
}

\author{
Tomas Frejka ${ }^{1}$ \\ Gérard Calot ${ }^{2}$
}

\begin{abstract}
Total fertility rates were declining from peaks experienced by early 1930s cohorts for 20 successive cohorts. The decline ceased among the 1950s and 1960s cohorts, because fertility deficits of young women were compensated with increased fertility when women reached their late twenties and thirties. The relative stability of completed fertility of these cohorts is attributed to Nordic social policies. Fertility deficits of young women in 1970s cohorts are comparatively large. For their completed fertility to be similar to that of earlier ones, there is considerably more catching up to do. What remains an open issue is whether social policies will be sufficiently effective for couples born in the late 1960s and the 1970s to have births not born earlier in their lives.
\end{abstract}

International Consultant, Visiting Scholar at the Max-Planck-Institute for Demographic Research, Germany. Email: Tfrejka@aol.com

2 (Former) Director, L’Observatoire Démographique Européen, France. (deceased, March 2001) 


\section{Introduction}

A number of studies have revealed that reproductive patterns of the populations of the Nordic countries in many ways resemble those of other European countries, but that they also have numerous distinctive features (see, for instance, Chesnais 1992; Coale and Watkins 1986; Katus 1997). Not surprisingly, the authors of this paper came to the same conclusion during the past one and a half years while working on an extensive project (Note 1) exploring in detail cohort fertility behavior in approximately 30 populations of Europe, North America, Oceania and East Asia (Note 2). The rationale for the project, its principal content, methods, a general overview of trends in cohort fertility, three abbreviated examples of country analyses and preliminary conclusions were published in Frejka, Calot (2001), a paper briefly summarized below. The principal objective of the present paper is to describe and analyze the idiosyncrasies as well as the common features of cohort fertility developments in the four large Nordic countries of Europe: Denmark, Finland, Norway and Sweden within the context of the overarching project. The paper is a modified version of what will be the section on the Nordic countries in a forthcoming book.

The rationale for the project derives from the fact that during the past several decades relatively limited attention has been devoted to cohort fertility behavior. In part that was due to a scarcity of long enough time series of appropriate data. As many of the low fertility countries have been accumulating sufficiently detailed data at least since the middle of the $20^{\text {th }}$ century, if not longer, reasonably comprehensive cohort fertility analyses can now be conducted. It was assumed that such investigations will provide meaningful complementary knowledge to the existing huge body of research on period fertility levels and trends.

The analytical methods are designed to make cohort analysis an appropriate tool for capturing not only past but also contemporary fertility behavior. In distinction to previous such analyses, the project complements data for cohorts that have reached the end of their reproductive period with estimates of total cohort fertility rates (TCFRs) for cohorts that were in their forties, possibly late thirties. Such estimates are made with the qualification that only less than 15 percent of the estimated TCFR needs to be estimated (Note 3). Furthermore, the analysis encompasses cohort fertility of women starting out on, or proceeding through, their reproductive behavior paths. Finally, the study analyzes cohort parity distributions and parity progression ratios, again to the extent reasonable employing estimates, and among women who are at the onset or in the middle of their reproductive periods.

In general, levels, trends and age patterns of cohort fertility for the generations born between 1930 and 1960 in "western" societies differed from those in the formerly socialist ones. In most western countries the decline of completed cohort fertility has 
been in progress starting with cohorts born in the 1930s and the generations born around 1960 are likely to complete their fertility with values decidedly below the replacement level. Cohorts born in the 1940s and mainly in the 1950s, increasingly postponed child-bearing, i. e. their fertility was relatively low while they were in their early to mid-twenties and high when in their late twenties and thirties. In some countries only a part of the accumulated early fertility deficit was later compensated. In the formerly socialist countries of Central and Eastern Europe, completed cohort fertility remained within narrow bands, usually around the replacement level, and was relatively steady among the cohorts born in the 1930s until the cohorts of the late 1950s. In comparison to the West, the lowering of fertility at younger ages started with cohorts born later, namely with those born in the late 1950s and early 1960s. The fertility deficit at younger ages is pronounced for the cohorts born in the 1960s.

In almost all industrialized and post-industrial societies cohorts born during the 1960s and in the 1970s are experiencing lower fertility up to comparable ages than previous cohorts. It is likely that a part of the deficits of the cohorts born in the mid- to late 1960s and in the 1970s will be compensated when these women will be older, however, it is equally likely that it will be only a relatively small fraction of the deficits that will be compensated. Consequently, it is almost certain that completed cohort fertility of the generations born during the 1960s and 1970s will be lower than for previous ones, i.e. their TCFRs will most likely be considerably below the replacement level. The parity distribution of children of successive cohorts is changing in favor of childlessness and increasing proportions of women who are having only one or two children.

The features and trends of cohort fertility behavior tend to differ regionally. One group of countries, which differs in specific ways from the others, is the region of the Nordic countries. An important distinctive feature of the Nordic countries is that the cohorts of women born in the 1950s and around 1960 actually compensated the entire fertility deficit accumulated when they were young. In the remainder of this paper we will analyze the cohort fertility behavior of this region. In the appendices 1 to 4 cohort fertility trends of the individual countries are analyzed.

\section{General features of the social and economic environment in the Nordic countries}

At the end of the $20^{\text {th }}$ century the inhabitants of Denmark, Finland, Norway and Sweden were among the wealthiest, healthiest, best educated, and experiencing the most favorable political and social conditions in the world. Their economies were modern and their people were enjoying relatively high incomes, between $\$ 20,000$ and 25,000 of 
gross domestic product per person in purchasing power parity. Their infant mortality rate was around 4 deaths per 1000 live births, female life expectancy at birth was around 80 and male life expectancy about 75 years. An Organization for Economic Cooperation and Development (2000) survey ranked Sweden, Denmark and Norway in the first to third places and Finland in the $7^{\text {th }}$ place with respect to adult literacy and skill levels among 20 of the most advanced countries. While these societies no doubt have a modicum of political tensions and problems they are among the best functioning and efficient democracies. The social welfare systems, although having been questioned as possibly excessive, were such that according to a UNICEF (2000) report these countries had the lowest levels of relative child poverty in the world with Sweden, Norway and Finland in the first to third places and Denmark in the sixth. These countries are also renowned as being the most gender egalitarian societies. More than in any other parts of the world, men participate in child-rearing and household activities. Most women, including those who have small children, tend to be employed outside the home, often full-time, and more than in other countries women are politically active.

It is quite obvious that the Nordic countries enjoy economic, social and political conditions more favorable and desirable than almost any other country in the world. What kind of impact are these conditions having on contemporary reproductive patterns and those of the recent past?

\section{Cohort fertility in the Nordic countries}

Fertility developments in each of the Nordic countries had their specifics and idiosyncrasies (Note 4), but they also shared many common features. At the end of the $20^{\text {th }}$ century the Nordic countries were at or close to their historic lows in period and completed cohort fertility. Similarly to other low fertility countries, total cohort fertility rates (TCFRs) were declining from the peak rates, typically experienced by the generations born around 1930, i.e. those which started their childbearing during the first years after the Second World War, for at least 20 successive cohorts (Table NC-1). The TCFRs of the 1950-51 birth cohorts in the Nordic countries were lower than the TCFRs of the 1930s birth cohorts by similar orders of magnitude as in many other countries. Contrary to the other countries, however, cohort fertility did not continue its decline in the Nordic countries among the cohorts of the 1950s. For instance, the total cohort fertility rate in Denmark was identical for the 1950-51 and 1960-61 birth cohorts; in Norway it was only one per cent lower in the 1960-61 compared to the 1950-51 cohort; and in Finland and Sweden it was five and one per cent higher, respectively (Table NC1). In practically all the other low fertility countries the decrease of the TCFRs was 
maintained among the cohorts of the 1950s as shown by examples, which are representative of groups of countries, listed in Table NC-1.

Table NC-1: Total cohort fertility rates, Nordic and selected "western" countries, birth cohorts 1930-31, 1950-51 and 1960-61

\begin{tabular}{lrrrrr}
\hline & \multicolumn{2}{c}{$\begin{array}{c}\text { Total cohort fertility rate (TCFR) } \\
\text { of birth cohort }\end{array}$} & $\begin{array}{r}\text { Change of TCFR compared } \\
\text { to older cohort (in per cent) }\end{array}$ \\
\cline { 2 - 6 } Country & $1930-31$ & $1950-51$ & $1960-61$ & $\begin{array}{r}1950-51 / \\
1930-31\end{array}$ & $1960-61 /$ \\
& & & & & $1950-51$ \\
\hline$\quad$ Nordic countries & 2.37 & 1.90 & 1.90 & -20 & - \\
Denmark & 2.45 & 1.85 & 1.94 & -24 & +5 \\
Finland & 2.51 & 2.09 & 2.06 & -17 & -1 \\
Nonway & 2.13 & 2.01 & 2.02 & -6 & +1 \\
Sweden & 3.06 & 2.33 & 2.12 & -24 & -9 \\
$\quad$ Selected "western" countries & 2.35 & 2.05 & 1.94 & -13 & -5 \\
Australia & 2.15 & 1.69 & 1.59 & -21 & -6 \\
England \& Wales & 2.27 & 1.86 & 1.61 & -18 & -13 \\
Germany, ex-FR & & & & & \\
Italy & & & & & \\
\hline
\end{tabular}

The demographic mechanism which underlies the difference between the Nordic countries and the other "Western" countries is the following. Starting with the cohorts born in the 1940s there was a strong tendency to lower fertility at younger ages practically in all "western" countries, including the Nordic ones. This propensity persisted in almost all countries and was still evident among the cohorts born in the early 1960s. Furthermore, a propensity to compensate at least part of the deficit (Note 5) when women reached their late twenties or thirties was also apparent. In no country, however, did the cohorts of the 1940s fully make up the deficit which they incurred when they were young.

The Nordic countries were unique because contrary to most other "western" countries the birth cohorts of the 1950s actually caught up with the older ones. In Denmark, for instance, by age 26 the 1960-61 birth cohort had incurred a deficit of 0.4 children compared to the 1950-51 cohort, but after that age the deficit was fully eliminated (Tables DK-1 and NC-2 and Figure DK-5). Developments in Norway were similar (Tables N-1 and NC-2 and Figure N-4). In Sweden the tendency to lower fertility when women were young was not as strong as in Denmark and Norway. More importantly, in Sweden the tendency to make up the birth deficit was already quite forceful among the cohorts born during the 1940s and the cohorts of the 1950s made up the whole deficit and even a little more (Tables S-1 and NC-2 and Figure S-5). In Finland the propensity to lower births was notable among the cohorts of the 1940s and 
weakened among the 1950 s cohorts. The net result was that, for example, the 1950-51 cohort made up about half of its deficit compared to the 1940-41 one (Tables F-1 and NC-2 and Figure F-4); and the 1960-61 birth cohort made up about one and a half times its deficit after age 26, but the deficit was comparatively small, only about 0.2 of a child (Tables F-1 and NC-2 and Figure F-4).

Table NC-2: Net fertility deficits and surpluses comparing birth cohorts, Nordic and selected "western" countries, cohorts 1930-31, 1940-41, 1950-51 and 1960-61 (in children per woman)

\begin{tabular}{|c|c|c|c|c|c|}
\hline \multirow[b]{2}{*}{ Country } & \multicolumn{3}{|c|}{$\begin{array}{l}\text { Net fertility deficit or surplus comparing } \\
\text { cohorts (children per woman) }\end{array}$} & \multicolumn{2}{|c|}{$\begin{array}{r}\text { Proportion of deficit made } \\
\text { up by surplus (percent) }\end{array}$} \\
\hline & $\begin{array}{r}1930-31 \text { and } \\
1940-41\end{array}$ & $\begin{array}{r}1940-41 \text { and } \\
1950-51\end{array}$ & $\begin{array}{r}1950-51 \text { and } \\
1960-61\end{array}$ & $\begin{array}{r}1950-51 \\
\text { cohort }\end{array}$ & $\begin{array}{r}1960-61 \\
\text { cohort }\end{array}$ \\
\hline \multicolumn{6}{|l|}{ Nordic countries } \\
\hline Denmark & -0.141 & -0.328 & -0.001 & 11 & 100 \\
\hline Finland & -0.445 & -0.149 & +0.087 & 48 & 147 \\
\hline Norway & -0.081 & -0.341 & -0.001 & 9 & 99 \\
\hline Sweden & -0.096 & -0.030 & +0.017 & 78 & 108 \\
\hline \multicolumn{6}{|c|}{ Selected "western" countries } \\
\hline Australia & -0.463 & -0.338 & -0.207 & 21 & 49 \\
\hline England \& Wales & -0.022 & -0.279 & -0.108 & 21 & 55 \\
\hline Ex-FRG & -0.177 & -0.274 & -0.100 & 9 & 64 \\
\hline Italy & -0.164 & -0.252 & -0.243 & n. a. & 24 \\
\hline
\end{tabular}

What is the cohort fertility experience of the generations that are initiating their child bearing or are in the middle of their reproductive years in the Nordic countries compared to other "western" countries? The first row in Table NC-3 confirms the above conclusion that the 1960-61 birth cohort in the Nordic countries attained the same or even somewhat higher completed fertility as the cohort born 10 years earlier, which was not the case in other countries. Already at age 36, the last year for which registration data are available (in most countries) for the 1960-61 cohort, it was clear that this would happen. In the Nordic countries the differences in cumulated cohort fertility rates (CCFRs) of the 1960-61 cohort compared to the 1950-51 cohort for age 36 were around zero, whereas in the other countries they were around minus 10 per cent (Table NC-3). 
Table NC-3: Difference in cumulated cohort fertility rates (CCFRs) compared to cohorts born 10 years earlier, Nordic and selected "western" countries, birth cohorts 1960-61, 1965-66, 1970-71 and 1975-76 (in per cent)

\begin{tabular}{|c|c|c|c|c|c|c|c|c|c|}
\hline \multirow[b]{3}{*}{$\begin{array}{l}\text { Birth } \\
\text { cohort }\end{array}$} & \multirow[b]{3}{*}{ Age } & \multicolumn{8}{|c|}{ Difference in CCFR compared to cohort born 10 years earlier in per cent in } \\
\hline & & \multicolumn{4}{|c|}{ Nordic countries } & \multicolumn{4}{|c|}{ selected "western" countries } \\
\hline & & Den. & Finl. & Norw. & Swd. & Australia & $\begin{array}{l}\text { Engl./ } \\
\text { Wales }\end{array}$ & Ex-FRG & Italy $^{2}$ \\
\hline $1960-61$ & 36 & -2 & +3 & -2 & +1 & -11 & -7 & -8 & -13 \\
\hline $1965-66$ & 31 & -5 & -7 & -7 & -5 & -20 & -14 & -18 & -26 \\
\hline $1970-71$ & 26 & -21 & -16 & -18 & -16 & -30 & -17 & -28 & -47 \\
\hline $1975-76$ & 21 & -15 & -17 & -26 & -31 & -19 & 0 & +12 & -57 \\
\hline Estimate & & & & & & & & & \\
\hline 1960 & 50 & 1.90 & 1.94 & 2.09 & 2.02 & 2.12 & 1.94 & 1.59 & 1.61 \\
\hline CCFR & & & & & & & & & \\
\hline
\end{tabular}

The propensity for cohort fertility to catch up with older generations continued to be much more pronounced in the Nordic countries compared to the other "western" ones among the cohorts born in the early to mid-1960s. The differences between the CCFRs of the 1965-66 birth cohorts compared to cohorts ten years older at age 31 were between -5 and -7 percent in the Nordic countries, compared to between -14 and -26 in the countries selected for comparison (Table NC-3).

The data for the cohorts born in the 1970s, which are embarking on their reproductive experiences in the 1990s, have to be interpreted with great caution. What appears to be clear is that the propensity for young women to have lower fertility continues to be strong in the Nordic countries. At age 26 and at age 21 the CCFRs are considerably lower than for the cohorts born ten years earlier in all the Nordic countries (Table NC-3). Compared to the other countries, at age 26 the propensity to postpone births appears even more pronounced elsewhere. At age 21, however, cumulated fertility in England \& Wales and in former West Germany appears to have bottomed out and is no longer declining in the 1975-76 cohort. On the other hand, in Italy the CCFR for the youngest cohort is much lower than for the cohort born ten years earlier.

Given the importance of the issue of likely future trends of fertility (period and cohort), a more detailed analysis appears justified. That the fertility decline has been considerable among the cohorts born during the late 1960s in the Nordic countries is illustrated by the low level of cumulated fertility by age 26 in the 1970-71 cohorts. By age 26 the 1970-71 birth cohorts in the Nordic countries had accumulated between 0.60 and 0.75 children per woman. The cumulated cohort fertility rates (CCFRs) at this age were about 15 to 20 per cent lower than in the 1960-61 cohort and 30 to 50 per cent 
lower than in the 1950-51 generation (Table NC-4). The differences in CCFRs between generations are somewhat smaller in the Nordic compared to the other "western" countries. In absolute terms the level of cumulated fertility by age 26 is at a similar level as in the other "western" countries and the differences between generations are also quite comparable. Past experience indicates that these generations are likely to have a propensity to bear a proportion of the children which were not born earlier. The problem is that deficits recorded by the 1970-71 birth cohorts are considerably larger than the equivalents for the 1960-61 cohorts. Therefore, if completed cohort fertility of this generation is to be similar to that of the 1960-61 cohort, it has more catching up to accomplish.

Table NC-4: Cumulated cohort fertility rates (CCFRs) at age 26, Nordic and selected "western" countries, birth cohorts 1950-51, 1960-61 and 1970-71

\begin{tabular}{|c|c|c|c|c|c|c|c|c|}
\hline \multirow{2}{*}{ Country } & \multicolumn{3}{|c|}{$\begin{array}{l}\text { CCFR of birth cohort } \\
\text { at age } 26\end{array}$} & \multicolumn{3}{|c|}{$\begin{array}{l}\text { Difference of CCFRs } \\
\text { between birth cohorts } \\
\text { (in per cent) }\end{array}$} & \multicolumn{2}{|c|}{$\begin{array}{l}\text { Difference of CCFRs } \\
\text { between birth cohorts } \\
\text { (in children per woman) }\end{array}$} \\
\hline & $\begin{array}{l}\text { L్ } \\
\text { 仓े } \\
\text { ᄋ̆ }\end{array}$ & $\begin{array}{l}\overline{0} \\
\vdots \\
\varnothing \\
\end{array}$ & 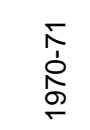 & 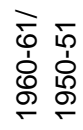 & 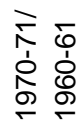 & 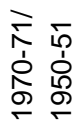 & 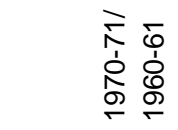 & $\begin{array}{l}\bar{r} \\
\hat{1} \\
\hat{i} \\
0 \\
0 \\
0\end{array}$ \\
\hline \multicolumn{9}{|c|}{ Nordic countries } \\
\hline Denmark & 1.143 & 0.761 & 0.600 & -33 & -21 & -48 & -0.16 & -0.54 \\
\hline Finland & 0.946 & 0.761 & 0.638 & -20 & -16 & -33 & -0.12 & -0.31 \\
\hline Norway & 1.258 & 0.908 & 0.743 & -28 & -18 & -41 & -0.17 & -0.52 \\
\hline Sweden & 1.052 & 0.793 & 0.665 & -25 & -16 & -37 & -0.13 & -0.39 \\
\hline \multicolumn{9}{|c|}{ Selected "western" countries } \\
\hline Australia & 1.349 & 0.918 & 0.646 & -32 & -30 & -52 & -0.27 & -0.70 \\
\hline $\begin{array}{l}\text { England \& } \\
\text { Wales }\end{array}$ & 1.151 & 0.911 & 0.755 & -21 & -17 & -34 & -0.16 & -0.40 \\
\hline Ex-FRG & 0.940 & 0.662 & 0.478 & -30 & -28 & -49 & -0.18 & -0.46 \\
\hline Italy ${ }^{a}$ & 1.061 & 0.835 & 0.445 & -21 & -47 & -58 & -0.39 & -0.58 \\
\hline
\end{tabular}

The data in table NC-5 provide a somewhat different perspective on the issues discussed above. In the first place, the data confirm that women born in the 1930s had children earlier than previous cohorts. Thus the 1940-41 birth cohorts of the four 
countries had borne a larger proportion of their eventual total cohort fertility by completed age 26 than the 1930-31 cohorts, namely 60 to 65 percent compared to 46 to 56 percent, respectively. Beginning with the birth cohorts of the 1940s and then mainly the 1950s cohorts of women had their children later in their reproductive period. The proportion of children of the eventual total cohort fertility rate born by completed age 26 of the 1960-61 cohorts was between 39 and 44 percent. A very low proportion by historical standards.

The data in Table NC-5 also demonstrate how rapidly the age patterns of cohort fertility were changing during the second half of the $20^{\text {th }}$ century. The increase of fertility in absolute and relative terms at younger ages by the cohorts of the 1930s is obvious from the rapid increase in the proportions born before completed age 26 in the 1940-41 cohorts compared to the 1930-31 cohorts. These were the generations that brought about the mid-century baby booms. Arguably even more remarkable is the stark decline in the proportions born before completed age 26 experienced mainly by the cohorts born in the 1950s. Basically in all the Nordic countries there was a reversal in the value of the proportions born before and after completed age 26 within a span of about 10 annual cohorts. In the table this is exemplified by Denmark where 60 percent of children were born before completed age 26 by women of the 1950-51 birth cohort compared to the cohort born ten years later which bore only 40 percent of its children by the same age.

Table NC-5: The proportion of childbearing realized by age 26, Nordic countries, birth cohorts 1930-31, 1940-41, 1950-51 and 1960-61

\begin{tabular}{lrrrr}
\hline & Proportion of childbearing of birth cohort by completed age 26 \\
Country & $1930-31$ & $1940-41$ & $1950-51$ & $1960-61$ \\
\hline Denmark & 56.3 & 65.0 & 60.3 & 40.1 \\
Finland & 51.8 & 61.9 & 51.0 & 40.1 \\
Norway & 46.1 & 61.3 & 60.3 & 43.6 \\
Sweden & 52.2 & 59.3 & 52.5 & 39.2 \\
\hline
\end{tabular}

A further question of interest is whether the value of the cumulated fertility rate by age 26 can provide any sense of what eventual total cohort fertility will be. In other words, is there a positive correlation between the value of cumulated fertility at age 26 with the eventual total fertility rate of the respective cohort? The experience of the 1950-51 and the 1960-61 birth cohorts indicates that there is no such correlation between the two measures. In all the Nordic countries the TCFR of the 1960-61 cohort was either the same or even slightly higher than that of the 1950-51 cohort (Table NC-1), although by age 26 the value of cumulated fertility of the 1960-61 generation was 20 to 33 percent 
lower than in the older cohort (Table NC-4). From Table NC-5 it is known that the proportion of children born by age 26 in the 1960-61 cohorts was only about 40 percent, i.e. that 60 per cent of children were born after that age. It is also known that the cumulated fertility rate by age 26 of the cohorts born during the 1960 s has continued to decline. That implies that considerably more than 60 percent of total cohort fertility would have to be produced by women in their late twenties and in their thirties if the TCFRs of the 1970s generations were to resemble those of the 1950s and early 1960s.

Cumulated cohort fertility for the youngest generations is also very low in the Nordic countries. For the 1975-76 birth cohort the CCFR at age 21 was 9 to 38 percent below the value at that age for the 1970-71 cohorts, 41 to 46 per cent below that of the 1960-61 cohorts and 60 to 70 per cent below the value for the 1950-51 generation (Table NC-6). The level of the CCFRs in the Nordic countries for this generation was lower than in Australia and England \& Wales, close to the level in the former Federal Republic of Germany. Fertility of women of the youngest generations in the Nordic countries was lower than that of any previous generation. This implies that cohorts born in the mid-1970s would have to have extremely high fertility in the future in order to make up the deficits incurred in the mid- to late 1990s.

Table NC-6: Cumulated cohort fertility rates (CCFRs) at age 21, Nordic and selected "western" countries, birth cohorts 1950-51, 1960-61 and 1975-76

\begin{tabular}{|c|c|c|c|c|c|c|c|}
\hline \multirow{3}{*}{ Country } & \multicolumn{4}{|c|}{ CCFR of birth cohort at age 21} & \multicolumn{3}{|c|}{$\begin{array}{l}\text { Difference of CCFRs between } \\
\text { birth cohorts (in per cent) }\end{array}$} \\
\hline & & & & & 1975-76/ & 1975-76/ & 1975-76/ \\
\hline & $1950-51$ & $1960-61$ & $1970-71$ & $1975-76$ & $1970-71$ & $1960-61$ & $1950-51$ \\
\hline \multicolumn{8}{|c|}{ Nordic countries } \\
\hline Denmark & 0.403 & 0.224 & 0.132 & 0.120 & -9 & -46 & -70 \\
\hline Finland & 0.352 & 0.236 & 0.162 & 0.140 & -14 & -41 & -60 \\
\hline Norway & 0.515 & 0.307 & 0.216 & 0.174 & -19 & -43 & -66 \\
\hline Sweden & 0.387 & 0.220 & 0.189 & 0.118 & -38 & -46 & -70 \\
\hline \multicolumn{8}{|c|}{ Selected "western" countries } \\
\hline Australia & 0.533 & 0.298 & 0.213 & 0.199 & -6 & -33 & -62 \\
\hline $\begin{array}{l}\text { England \& } \\
\text { Wales }\end{array}$ & 0.494 & 0.326 & 0.300 & 0.285 & -5 & -13 & -43 \\
\hline Ex-FRG & 0.396 & 0.206 & 0.133 & 0.140 & +5 & -32 & -65 \\
\hline Italy ${ }^{a}$ & 0.311 & 0.310 & 0.122 & 0.085 & -30 & -73 & -73 \\
\hline
\end{tabular}


The declining total cohort fertility rates and cumulated cohort fertility rates of the young generations in the Nordic countries would not be possible without changes in parity distributions and parity progression ratios. It is generally known that the proportions of higher order births is declining. Data for Finland and Norway demonstrate the decline of the proportion of fourth and higher order children (Figure F7 and Table N-3). What is less known is the recent trend in the decline of first births. The other side of this development is, of course, an increase in the proportion of women that do not bear any children (Table NC-7). In Finland the proportion of all women who had a first child was over 90 percent among women born in the 1930s and the early 1940s (Figure F-7). Starting with the cohorts born in the late 1940s this proportion dropped below 90 percent and the robust estimates for the cohorts of the early to mid 1960s indicate that less than 80 percent of these cohorts will have at least one child. Interestingly, at least in Finland among the women having a first birth larger proportions go on to have second and third children. The parity progression ratios from first to second and from second to third births were increasing between the cohorts of the late 1940s to those of the late 1950s (Figure F-8).

Table NC-7: Proportion of women childless, selected Nordic and other countries, ages 30 and 40, birth cohorts 1940 to 1968

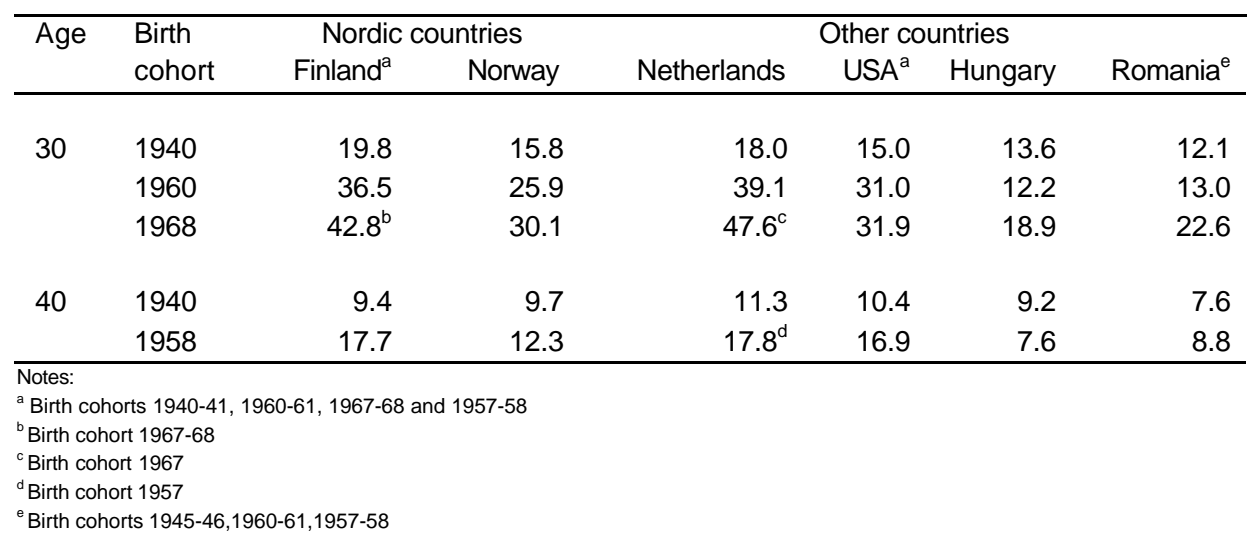

In the two countries for which we have data at this point there is a distinct increase in the proportions of childless women (Table NC-7 and Figure F-10). The cohorts born in 1958 at age 40 have practically reached the end of their childbearing. In Finland the proportion of childless women at that age of cohorts 18 years apart, i. e. the 1958 compared to the 1940 cohort, almost doubled. In Norway the respective increase was about 25 percent (Table NC-7). For women 30 years old comparisons can be made for 
cohorts up to 28 years apart, however a considerable amount of childbearing still takes place after that age. In the 1947-48 birth cohort three quarters of childbearing had taken place by age 30 . Even if the differences in childlessness between the cohorts were to narrow somewhat, it appears that a larger proportion of women born in 1968 will remain without children by the end of their childbearing periods than in the older cohorts in Finland and in Norway. The rather marked continuing trend of increasing childlessness in Finland is apparent in the curves for all ages in Figure F-10.

A comparison with other selected countries illustrates that trends in childlessness in Finland were similar to those in the Netherlands. Trends in Norway resembled somewhat trends in the United States. In selected Central and East European countries trends in childlessness were considerably different. Among the older cohorts the proportions of childless women had remained low, however, even in Hungary and Romania the youngest cohorts started to display increases in proportions childless, although with a time lag compared to the Nordic countries.

\section{Public policies and fertility in the Nordic countries}

The governments of all four Nordic countries claim that they did not have population policies or deliberate pronatalist policies (UNECE et al. 1993, 1998). All four countries do, however, have in common generous social welfare policies and a set of policy priorities impacting on reproductive behavior. These include the principle of gender equality, i.e. equal opportunities for men and women; a commitment to minimize conflicts between childbearing, child rearing, family responsibilities and careers, especially for women; and in general the implementation of family friendly policies.

The social reality of the Nordic countries reflects these priorities. Women are highly educated, the proportions of women with second and third level education have been increasing rapidly and in the 1990s were very similar to those of men. The proportions of women working outside the home are the highest in the world, almost as high as those of men. Women are also very active in public life, as mentioned in the Sweden appendix, following the 1994 elections 41 per cent of members of Parliament were women as were 11 of 22 cabinet members.

At the same time, compared to most other "western" advanced countries, period and cohort fertility in the Nordic countries during the last decade or two of the $20^{\text {th }}$ century was relatively high and stable. It is especially the stability of completed cohort fertility that stands out (Table NC-1). In all the Nordic countries completed cohort fertility of the generations born around 1960 was at least as high as that of the generations born around 1950, whereas in all other countries, except for the United States of America, the total cohort fertility rates were declining. In all "western" 
countries beginning with the birth cohorts of the 1940s there was a common propensity for women to have a larger proportion of their births later in the reproductive period. What distinguished the Nordic countries was that when women reached their late twenties and thirties they compensated for all the births not born when they were young (Table NC-2). There is a general consensus among knowledgeable experts that the Nordic social policies provided appropriate and propitious conditions for such an outcome. Hoem (1990) conducted a detailed analysis of the timing of second and third order births in Sweden and concluded that "recent demographic developments in Sweden can in part be attributed to the low-key and largely indirect pronatalism of Swedish social policies."

What remains an open issue is whether the social policies of the governments in the Nordic countries will be sufficiently influential for couples and women of the young generations, those born in the late 1960s and during the 1970s, to have all the births not born earlier in their life (Tables NC-3, NC-4 and NC-6). Not only is the propensity to lower fertility at young ages continuing among the cohorts born during the 1970s, but it is intensifying. The absolute levels of cumulated cohort fertility, for instance, at ages 21 and 26 continued to be lower for each successive generation (Tables NC-4 and NC-6). The cohorts of the 1970s would have to have higher fertility than the birth cohorts of the 1960s in their late twenties and during their thirties in order to have comparable total cohort fertility rates. Actual developments of the late 1990s do not point in that direction. Age specific fertility rates in the prime childbearing ages of between 27 and 32 have leveled off in Denmark and Norway, they have declined moderately in Finland and declined sharply in Sweden (Council of Europe 1999). For these trends to be reversed would probably require major strengthening of social policies and of practical measures.

\section{Achieving desired goals}

There are at least two ways to explore, neither of them ideal, whether desired or desirable fertility goals or intentions are actually being reached. On the individual level, women express their desired fertility in surveys, and on the societal level, one could, for instance, designate replacement level fertility as desirable.

Comparing the expected ultimate family size (of the Fertility and Family Surveys taken between 1988 and 1996 in the low fertility countries) and the actual estimated total cohort fertility rates, one can see that women in the Nordic countries were not more successful than women elsewhere in achieving their goals (Table NC-8). Their completed fertility will presumably be between 10 and 19 percent lower than their 
desired family size, whereas in a set of other countries where such comparisons can be made completed fertility will be lower by 4 to 23 percent.

Table NC-8: A comparison of expected ultimate family size, replacement level fertility and estimated total cohort fertility rates, Nordic and selected other countries, birth cohorts born around 1960

\begin{tabular}{|c|c|c|c|c|c|c|c|}
\hline \multicolumn{4}{|c|}{ Fertility and family survey } & \multirow[b]{2}{*}{ 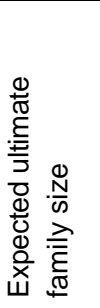 } & \multirow{2}{*}{ 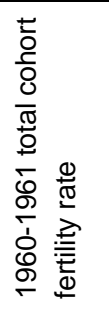 } & \multirow{2}{*}{ 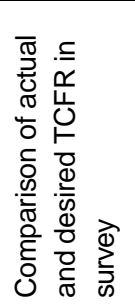 } & \multirow{2}{*}{ 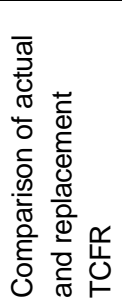 } \\
\hline Country & 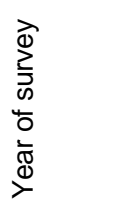 & 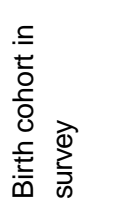 & 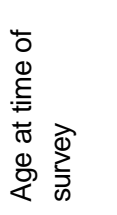 & & & & \\
\hline \multicolumn{8}{|c|}{ Nordic countries } \\
\hline Finland & 1989 & $1960-64$ & $25-29$ & 2.3 & 1.94 & -16 & -7 \\
\hline Norway & 1988 & 1960 & 28 & 2.3 & 2.06 & -10 & -1 \\
\hline Sweden & 1992 & 1959 & 33 & 2.5 & 2.02 & -19 & -3 \\
\hline \multicolumn{8}{|c|}{ Selected other countries } \\
\hline Austria & $1995-96$ & $1956-61$ & $35-39$ & 1.9 & 1.66 & -13 & -21 \\
\hline Belgium & 1991-92 & $1956-61$ & $30-34$ & 2.1 & 1.80 & -14 & -14 \\
\hline France & 1994 & $1959-63$ & $30-34$ & 2.3 & 2.09 & -9 & 0 \\
\hline Hungary & $1992-93$ & $1958-62$ & $30-34$ & 2.1 & 2.02 & -4 & -3 \\
\hline Netherlands & 1993 & $1958-63$ & $30-34$ & 2.11 & 1.84 & -13 & -12 \\
\hline Switzerland & 1994-95 & $1960-64$ & $30-34$ & 2.2 & 1.77 & -20 & -15 \\
\hline Spain & 1995 & $1955-60$ & $35-39$ & 2.2 & 1.70 & -23 & -19 \\
\hline
\end{tabular}

Taking the relative success of the cohorts born around 1960 in achieving replacement level fertility, the Nordic countries fared much better (Table NC-8). The total cohort fertility rates of the 1960 generation in the Nordic countries were lower than replacement fertility in the order of 1 to 7 percent, whereas in the majority of the other countries the relative difference from replacement fertility was much larger. 


\section{Concluding remarks}

In many respects cohort reproductive behavior in the Nordic countries is similar to that in other "Western" countries. The exception were the cohorts born during the 1950s and early 1960s which also had relatively low fertility when young but made up the whole deficit when they were in their late twenties and in their thirties.

To date the reproductive behavior of the youngest cohorts, those born in the late 1960s and in the 1970s, resembles that of other western countries. Despite the favorable economic, health and social conditions, and despite the relative gender equalities and the family friendly policies in the Nordic countries, cohort fertility of these young generations is very low, actually as low or lower than in many other countries. The open question is whether and how much of the early fertility deficits of these generations in the Nordic countries will be made up later in life. 


\section{Notes}

1. The working title of the project is "Contemporary cohort reproductive patterns: Low fertility countries in the second half of the $20^{\text {th }}$ and in the early $21^{\text {st }}$ century."

2. The countries are: Australia, Austria, Belgium, Bulgaria, The Czech Republic, Denmark, England and Wales, Finland, France, Greece, Hungary, Italy, Japan, The Netherlands, New Zealand, Norway, Portugal, The Slovak Republic, Spain, Sweden, Switzerland, Romania, Russian Federation, United States, Federal Republic of Yugoslavia, plus data for the former Federal Republic of Germany and for the former German Democratic Republic. We are still acquiring data for other countries, such as Canada, Hong Kong and Taiwan.

3. The majority of the measures used in the project are based on observed and recorded data. There are exceptions. For instance, in the series of total cohort fertility rates (TCFRs) small proportions of the most recent TCFRs are estimated. Typically, this will be done for the age-specific fertility rates of women in their late thirties and forties by applying the most recent recorded rate as the estimated rate. While obviously there is room for error, rigorous tests have proven that the errors are minor and do not affect the basic observations and analyses. In every country none other than the most recent TCFR contains an estimate of between 12 and 14 percent of its value. For each preceding cohort the estimated proportion of the TCFR declines rapidly. For the cohorts in their forties the estimated proportion tends to be under one percent of the TCFR which minimizes any possibility of error. Our tests have shown that indeed even for women in their late thirties the errors are very small. For details see Frejka, Calot (2001).

4. More detailed analyses of fertility trends are contained in Appendices 1 - 4 for Denmark, Finland, Norway and Sweden, respectively.

5. Changes in the age structure of cohort fertility can be observed by comparing agespecific fertility rates of one cohort with that of another. In this study as a rule cohorts born 10 years apart are compared. When the age-specific fertility rates of a cohort born later (a younger cohort) is higher than that of a cohort born earlier (an older cohort), the difference is considered a surplus. When the age-specific fertility rates of a cohort born later (a younger cohort) is lower than that of a cohort born earlier (an older cohort), the difference is considered a deficit. As a rule, whole age ranges in a younger cohort tend to be either higher or lower compared to the older cohort. 


\section{References}

Chesnais J.-C., 1992, The demographic transition, Clarendon Press, Oxford.

Chesnais, J.-C., 1996, "Fertility, family, and social policy in contemporary Western Europe," Population and Development Review, 22, 4: 729-739.

Coale, A. J., and S. C. Watkins,1986, The decline of fertility in Europe: the revised proceedings of a Conference on the Princeton European Fertility Project, Princeton: Princeton University Press, xxii +484.

Council of Europe, 1999, Recent demographic developments in Europe: 1999, Strasbourg

Denmark, 1993, "Country Statement," in United Nations Economic Commission for Europe, Council of Europe, European Population Conference, Vol. 2: 133-139.

Denmark, 1998, "Country Statement," in United Nations Economic Commission for Europe, UNFPA, Council of Europe, Hungarian Central Statistical Office, Regional Population Meeting, Budapest.

Frejka, T. and G. Calot, 2001, "Cohort Reproductive Patterns in Low-Fertility Countries," Population and Development Review, 27, 1: 103-132.

Granström, F., 1997, "Standard Country Report: Sweden," Fertility and Family Surveys in Countries of the ECE Region, Economic Studies 10b, United Nations, New York and Geneva.

Hoem, J.M., 1990, "Social policy and recent fertility change in Sweden," Population and Development Review, 16, 4: 735-748.

Katus, K., 1997, "Long-term fertility development in Baltoscandinavia," Yearbook of Population Research in Finland, 34: 18-34.

Lappegård, T., 2000, "New fertility trends in Norway," Demographic Research 2:3 (16 March)

Matthiessen, P.C., 1997, "Family formation and fertility in the Danish population since the mid-1960s" (in Danish), in P. L. Hjorth, E. Dal, and D. Favrholdt, eds., Fra Egtvedpigen til Folketinget, Copenhagen, Denmark: Det Kongelige Danske Videnskabernes Selskab, pp. 151-60.

Nikander, T., 1998, "Standard Country Report: Finland," Fertility and Family Surveys in Countries of the ECE Region, Economic Studies 10g, United Nations, New York and Geneva. 
Organization for Economic co-operation and Development, 2000, Literacy in the Information Age: Final Report of the International Literacy Survey, Paris: OECD

United Nations Children's Fund, 2000, Child Poverty, New York: UNICEF

United Nations Economic Commission for Europe, Council of Europe, 1993, European Population Conference, Geneva: United Nations

United Nations Economic Commission for Europe, UNFPA, Council of Europe, Hungarian Central Statistical Office, 1998, Regional Population Meeting, Budapest, Geneva: United Nations

United Nations Economic Commission for Europe, UNFPA, 1996-2000, Fertility and Family Surveys, Standard country reports, Economic Studies 10a - 10m, Geneva: United Nations 


\section{Appendix 1 - DENMARK}

Throughout the 19th century fertility was stable with a crude birth rate around 30 births per 1000 population. During the first decade of the 20th century the total period fertility rate (TPFR) was around 4 children per woman. It then declined rapidly to reach below replacement by the late 1920 s, i.e. in less than two decades. Fertility remained at that level throughout the 1930s, but recovered in the early 1940s and reached a peak in 1945-46 with a TPFR of about 3 children per woman (Chesnais 1992). The TPFR enjoyed two decades of stability at around $2.5-2.6$, but experienced a rapid decline between 1966 and 1970 and the decrease then became more moderate through the early 1980s, when the TPFR declined to around 1.4 (Fig. DK-1). This was followed by a period of increasing period fertility. In 1994 and 1995 the TPFR was at 1.8 and resumed a moderate decline in the late 1990s to 1.7 in 1998 and 1999.

Denmark has evolved into a prosperous, healthy and productive society. Its per capita gross domestic product (in purchasing power parity) was $\$ 23,300$ in 1998 , one of the highest in the world. In the late 1990s 70 per cent of its GDP was produced in the service sector where over 70 per cent of the population was employed. Both men and women have high labor force participation rates. Between 1966 and 1994 the labor force participation rate for married women increased from 50 to more than 90 per cent with a large proportion of these women working full-time (Matthiessen 1997).

The successive governments of Denmark have never promulgated a population policy "aimed at influencing the size, the growth, or the structure of population" (Denmark 1993). For several decades, however, extensive government welfare measures have been in place and these were being continuously expanded. Most recently, "since 1994 a number of reforms have been implemented to improve the situation for families with small children." For instance, parents can take a partly compensated leave up to one year to look after their child; many collective agreements include provisions to create more family friendly working conditions, such as paid leave to look after a sick relative; and the government has secured the possibility for all parents to have their children taken care of during working hours and thus from 1993 to 1998 140,000 new day-care places were provided (Denmark 1998).

The generations born in the 1920s had a total cohort fertility rate (TCFR) above the replacement level of between 2.3 and 2.4 children per woman (Figs. DK-1 and DK2). Starting with the birth cohorts of the mid-1930s the TCFR declined for almost 20 consecutive cohorts and the generations born in the mid-1950s had values slightly below 1.9 children per woman. Estimated TCFRs for the generations born around 1960 which are completing their childbearing in the late 1990s remained at that level.

Successive generations changed their age patterns of childbearing quite considerably. Despite a decline in completed fertility, the peak of childbearing 
remained stable at the ages 23 to 24 from the generations born in the late 1920s through those born around 1950, with age pattern changes occurring before and after the peak. Compared to older cohorts, those of the late 1930s and early 1940s had a large proportion of their children when they were young and once they reached their late twenties their fertility was relatively low. At ages 32 to 43 fertility at individual ages was 30 to 50 per cent lower in the 1940-41 compared to the 1930-31 cohort (Fig. DK$3)$.

The cohorts of the 1940s still had relatively high fertility as young teenagers, but in their late teens and particularly when in their twenties fertility was considerably lower than that of older generations. Between the ages of 18 to 25, at the peak of the reproductive period, fertility of the 1950-51 cohort was 15 to 35 percent lower than among women born in 1940-41. There was a slight tendency to catch up later in their lives when they were in their late thirties and early forties. In percentage terms there were some spectacular differences in fertility. For instance, at ages 40 to 43 fertility was between 110 and 160 per cent higher between these two generations, but this made little difference in cohort fertility, because only few children are born at those ages.

A major change in the age patterns of fertility took place among the birth cohorts of the 1950s. The propensity to postpone births when they were young was unmistakable and grew stronger from one birth cohort to the next. Equally vigorous was the propensity to eventually bear all the postponed children when these women were in their late twenties and in their thirties (Fig. DK-3). The childbearing peak, of the 196061 birth cohort had shifted distinctly to the right to ages 27-28. This shift is also conspicuous in the continuing upward trend of the average age of childbirth, which was at 29.4 on a cross-sectional basis in 1998 and at 28.5 for the 1960 birth cohort (Fig. DK-4). At ages 16 to 24 fertility of the 1960-61 cohort was 30 to almost 70 per cent lower at individual ages compared to the 1950-51 cohort. Subsequently, between the ages of 29 and 36 the difference was 40 to 100 per cent in the opposite direction. As a result completed fertility will apparently remain essentially unchanged for all the cohorts of the 1950s and early 1960s (Fig. DK-1).

Table DK-1 provides an overview of the changes in childbearing when comparing cohorts ten years apart in terms of absolute numbers (fractions) of children born. The 1940-41 birth cohort had a surplus of 0.122 children between the ages of 15-25 compared to the 1930-31 cohort. This surplus was offset by a deficit of 0.263 after age 25 , resulting in an overall deficit of 0.141 children per woman. The $1950-51$ cohort compared to the 1940-41 cohort had a large deficit of 0.378 children per woman between the ages of 18 and 33 and only a small part of that was compensated at ages outside of that age range, resulting in an overall deficit of 0.328 children per woman. In contrast, the 1960-61 cohort had relatively few children up to age 26 included with a deficit of 0.382 children compared to the 1950-51 cohort. Its comparative surplus after 
age 26 was of almost equal size and thus the total cohort fertility rates of these two cohorts were equal.

Table DK-1: Fertility deficits and surpluses comparing birth cohorts, Denmark, cohorts 1930-31, 1940-41, 1950-51 and 1960-61

\begin{tabular}{|c|c|c|c|c|c|c|}
\hline \multirow[b]{2}{*}{ Fertility } & \multicolumn{2}{|c|}{$\begin{array}{l}\text { Cohort 1930-31 and } \\
1940-41\end{array}$} & \multicolumn{2}{|c|}{$\begin{array}{l}\text { Cohort 1940-41 and } \\
1950-51\end{array}$} & \multicolumn{2}{|c|}{$\begin{array}{l}\text { Cohort 1950-51 and } \\
1960-61\end{array}$} \\
\hline & $\begin{array}{l}\text { Age } \\
\text { group }\end{array}$ & $\begin{array}{l}\text { Number of } \\
\text { children }\end{array}$ & $\begin{array}{l}\text { Age } \\
\text { group }\end{array}$ & $\begin{array}{l}\text { Number of } \\
\text { children }\end{array}$ & $\begin{array}{l}\text { Age } \\
\text { group }\end{array}$ & $\begin{array}{l}\text { Number of } \\
\text { children }\end{array}$ \\
\hline Deficit & $26-49$ & -0.263 & $18-33$ & -0.378 & $15-26$ & -0.382 \\
\hline Surplus & $15-25$ & +0.122 & $15-17$ & +0.008 & $27-49^{a}$ & +0.381 \\
\hline & & & $34-49$ & +0.042 & & \\
\hline Total & & -0.141 & & -0.328 & & -0.001 \\
\hline
\end{tabular}

Note: ${ }^{a}$ Includes estimated data for ages $37-49$ in the $1960-61$ cohort.

A complementary view of the described changes in the cohort age patterns of childbearing is depicted in Fig. DK-5. By age 27 the 1960-61 birth cohort had 0.4 less children than the 1950-51 cohort. By age 37 the deficit between the 2 generations was less than 0.05 children and our estimates indicate that the difference will be fully erased as just demonstrated in Table DK-1. The postponement of childbearing as well as the catching up at later ages are also manifest in the 1965-66 cohort. By age 26 this cohort had almost 0.5 children less than the 1950-51 generation but during their late twenties these women were at the peak of their childbearing with higher fertility than the 196061 cohort (Fig. DK-6). By age 32 the 1965-66 cohort had almost the same cumulated fertility as the 1960-61 cohort (Fig. DK-5) which indicates that these women have the potential to eventually match the completed fertility of the generations of the $1950 \mathrm{~s}$.

The propensity to postpone births continues to be displayed by the cohorts which were at the beginning of their childbearing periods during the 1990s. In figures DK-5 and DK-6 one can see that the 1970-71 cohort is on a childbearing path lower than that of the older generations and there is a first indication that the 1975-76 cohort is aiming for an even lower path. This is expressed in numerical terms in Table DK-2. Women of the 1970-71 cohort had 41 per cent less children by age 21 and 21 percent less by age 26 compared to women ten years older. Fertility of the youngest women, the 1975-76 birth cohort was also lower compared to the older cohort. It is impossible to predict how forceful the propensity to bear children later in life will be among the young generations. However, since these young generations have had relatively low fertility in 
their teens and early twenties, they would have to have unusually high fertility in their late twenties and thirties to catch up with the older generations.

Table DK-2: Cumulated cohort fertility rates at specified ages and relative changes compared to birth cohorts 10 years older, Denmark, cohorts 1960-61, 1965-66, 1970-71 and 1975-76.

\begin{tabular}{lllllllll}
\hline \multirow{2}{*}{ Age } & \multicolumn{3}{l}{ Cumulated fertility rate of birth cohort } & \multicolumn{5}{l}{$\begin{array}{l}\text { Change of CCFR compared to cohort ten } \\
\text { years older (in per cent) }\end{array}$} \\
\cline { 2 - 9 } & $1960-61$ & $1965-66$ & $1970-71$ & $1975-76$ & $1960-61$ & $1965-66$ & $1970-71$ & $1975-76$ \\
\hline 36 & 1.778 & n.a. & n.a. & n.a. & -2 & n.a. & n.a. & n.a. \\
31 & 1.399 & 1.371 & n.a. & n.a. & -14 & -5 & n.a. & n.a. \\
26 & 0.761 & 0.671 & 0.600 & n.a. & -33 & -29 & -21 & n.a. \\
21 & 0.224 & 0.142 & 0.132 & 0.120 & -44 & -56 & -41 & -15 \\
\hline
\end{tabular}


Figure DK-1: Total period fertility rate, Denmark, 1950-2000, and total cohort fertility rate in Danish birth cohorts 1919-65 lagged by the average age at childbearing

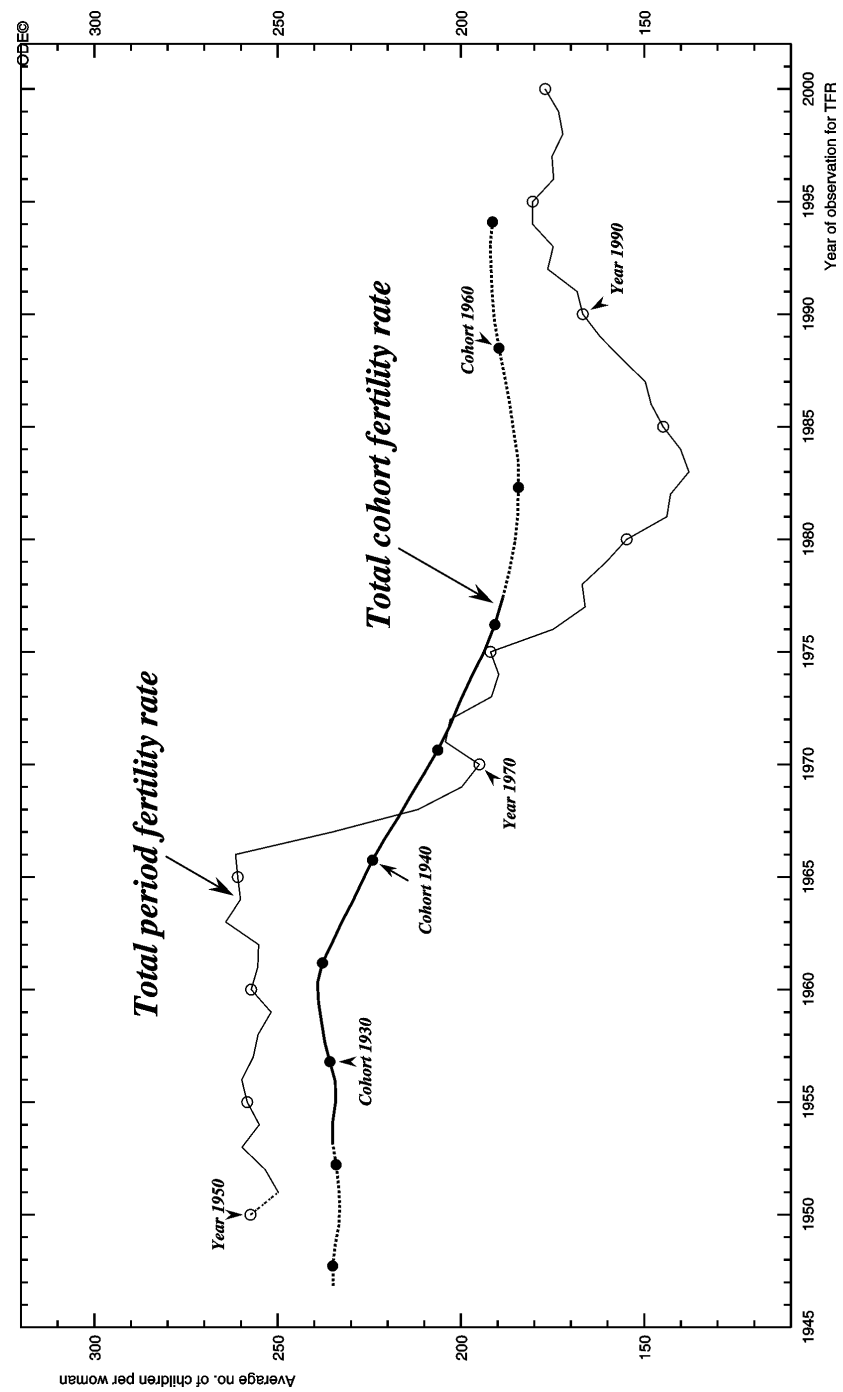

Note: Dotted lines indicate that a minor proportion of the respective TCFRs is based on estimates 
Figure DK-2: Cumulated cohort fertility at specified ages, Denmark, birth cohorts 1923-1975

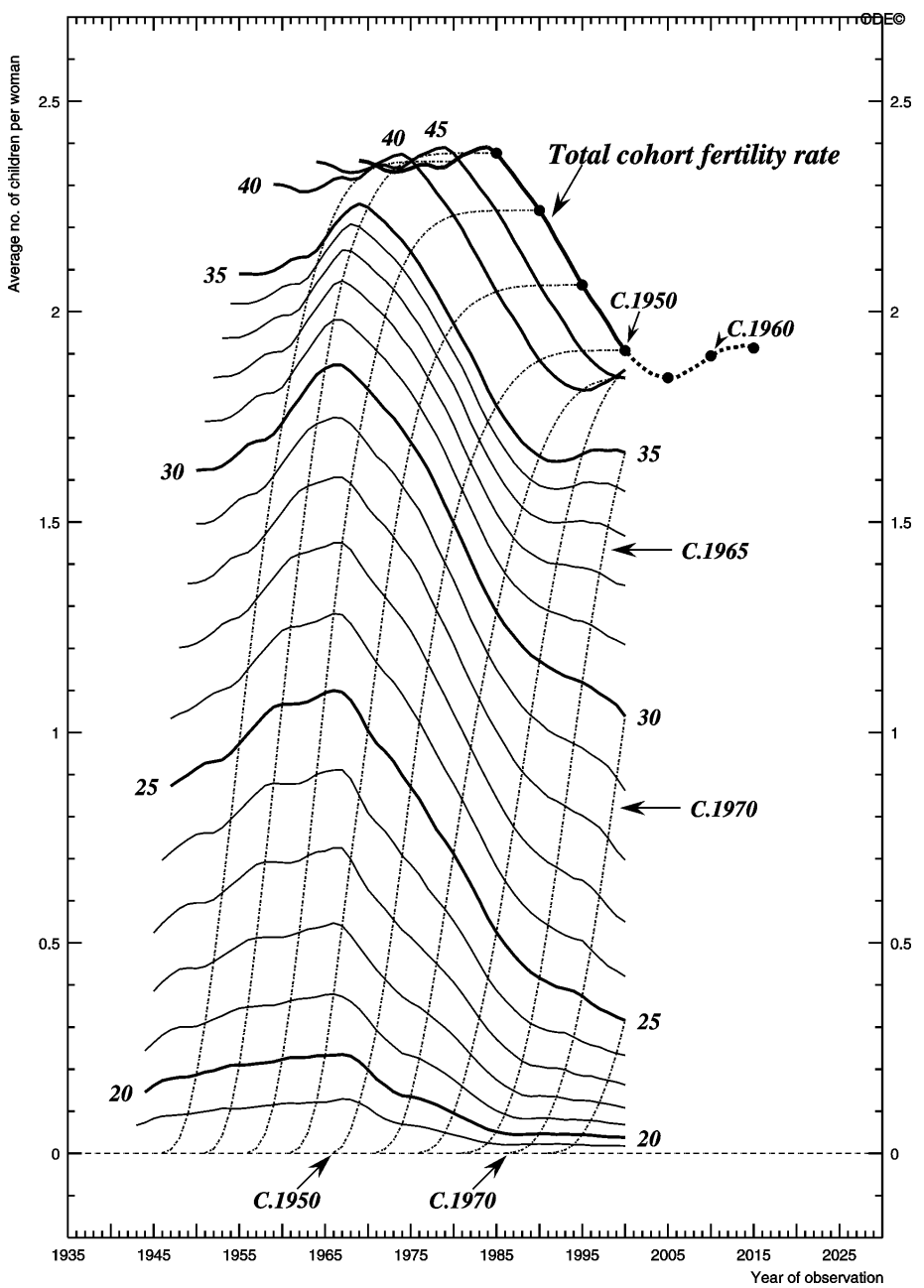

Note: The part of the TCFR line which is dotted indicates that a minor proportion of the TCFR is based on estimates 
Demographic Research - Volume 5, Article 5

Figure DK-3: Age-specific fertility rates, Denmark, birth cohorts 1930-31, 1940-41, 1950-51 and 1960-61

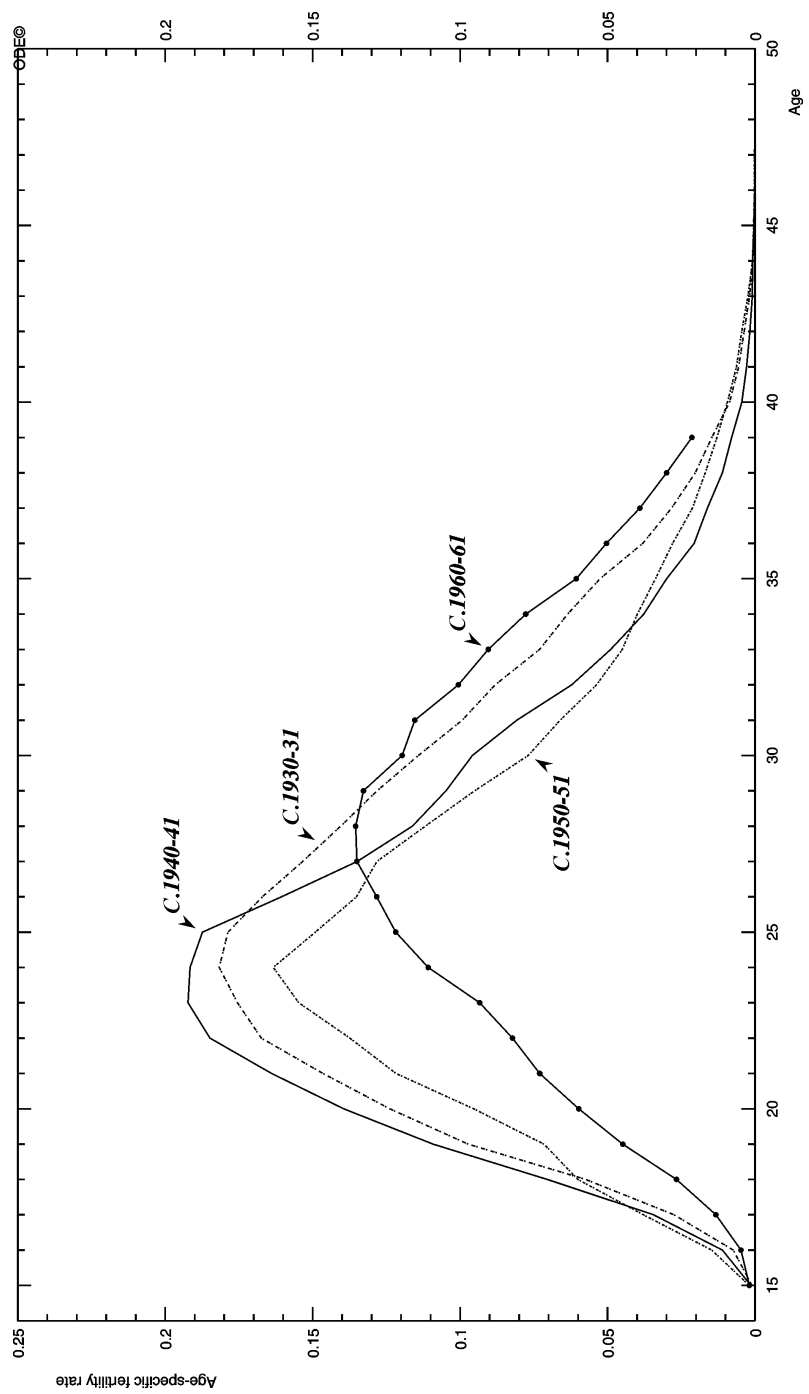


Figure DK-4: Period average age of childbearing, 1941-2000, cohort average age of childbearing, birth cohorts 1919-1965, Denmark

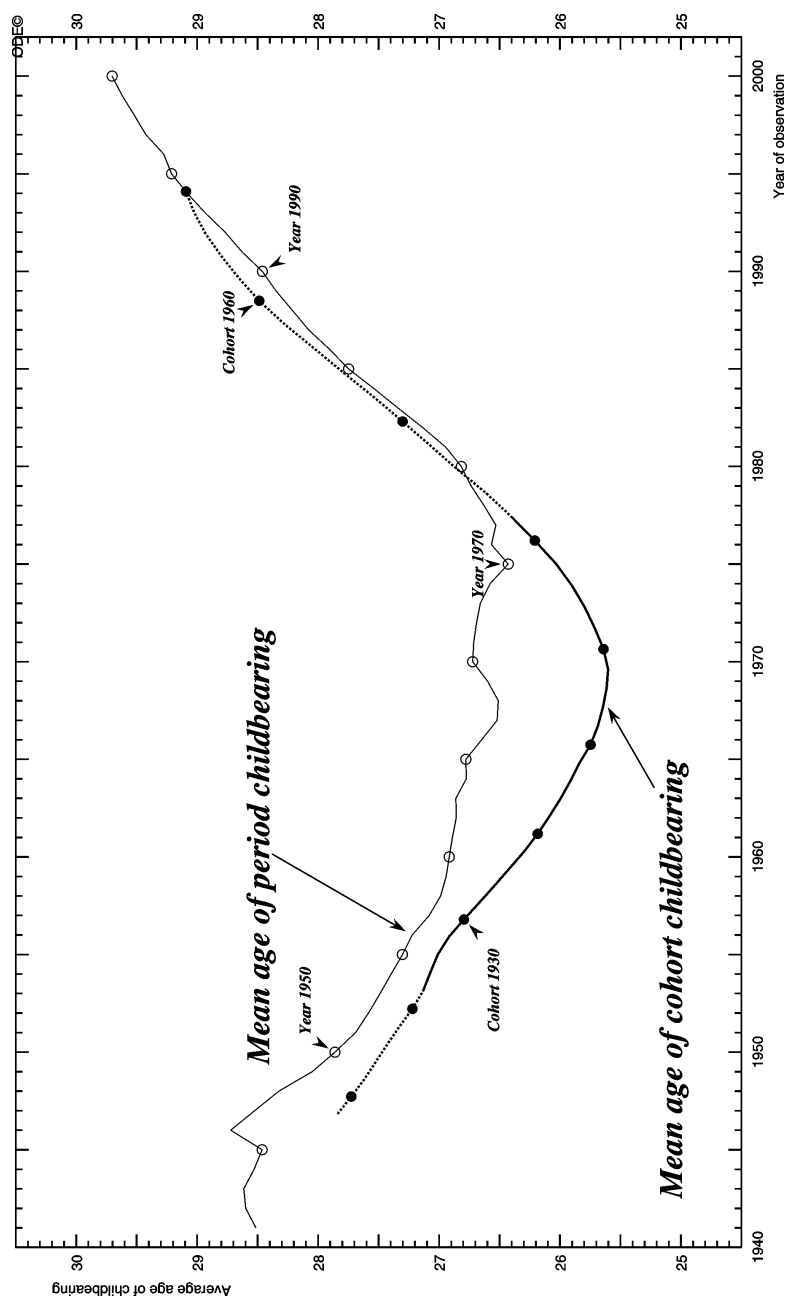

Note: The part of the "mean age of cohort childbearing" line which is dotted indicates that a minor proportion of the respective agespecific rates are based on estimates 
Figure DK-5: Differences in cumulative age-specific cohort fertility rates between base and subsequent cohorts: Denmark, women born in 1950-51 (base), 195556, 1960-61, 1965-66, 1970-71 and 1975-76

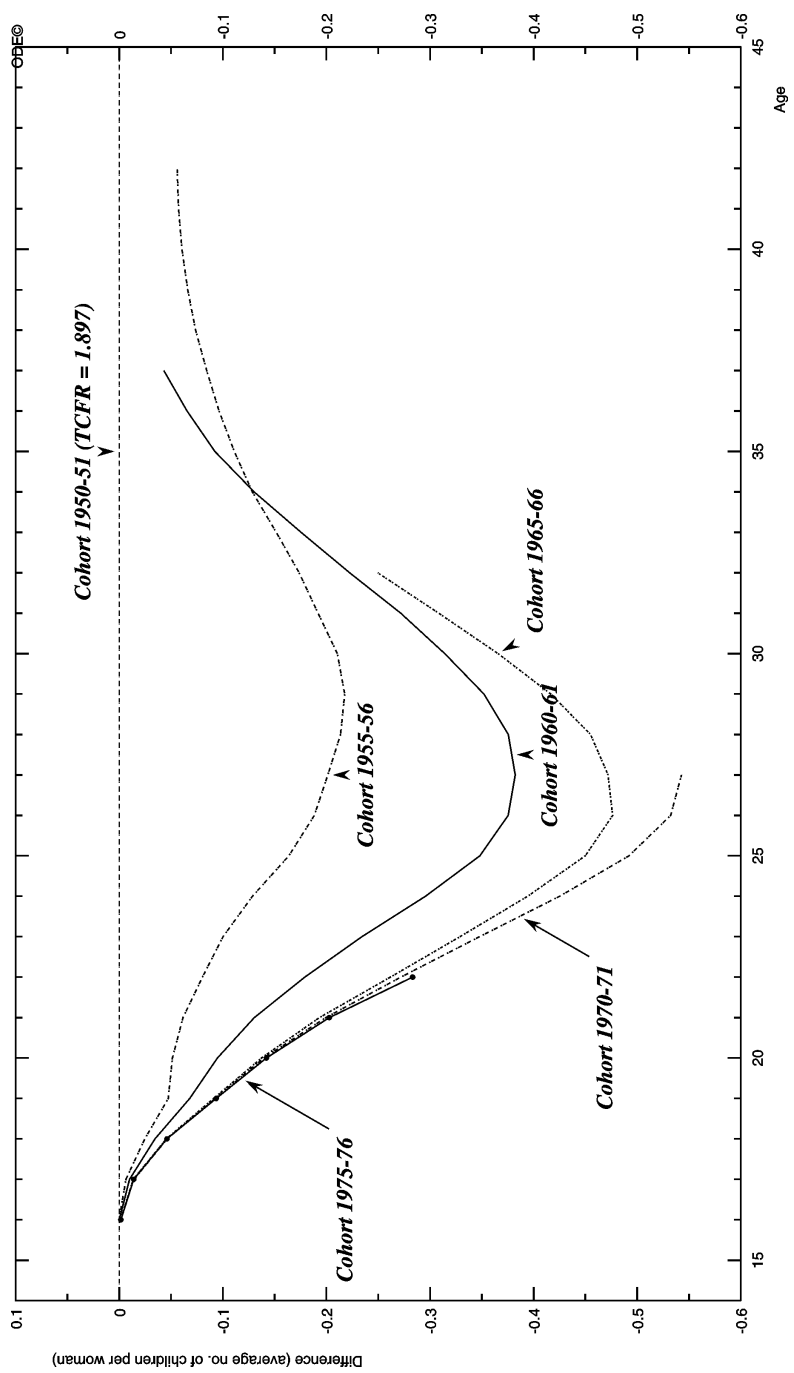


Figure DK-6: Age-specific fertility rates, Denmark, birth cohorts 1960-61,1965-66, 1970-71 and 1975-76

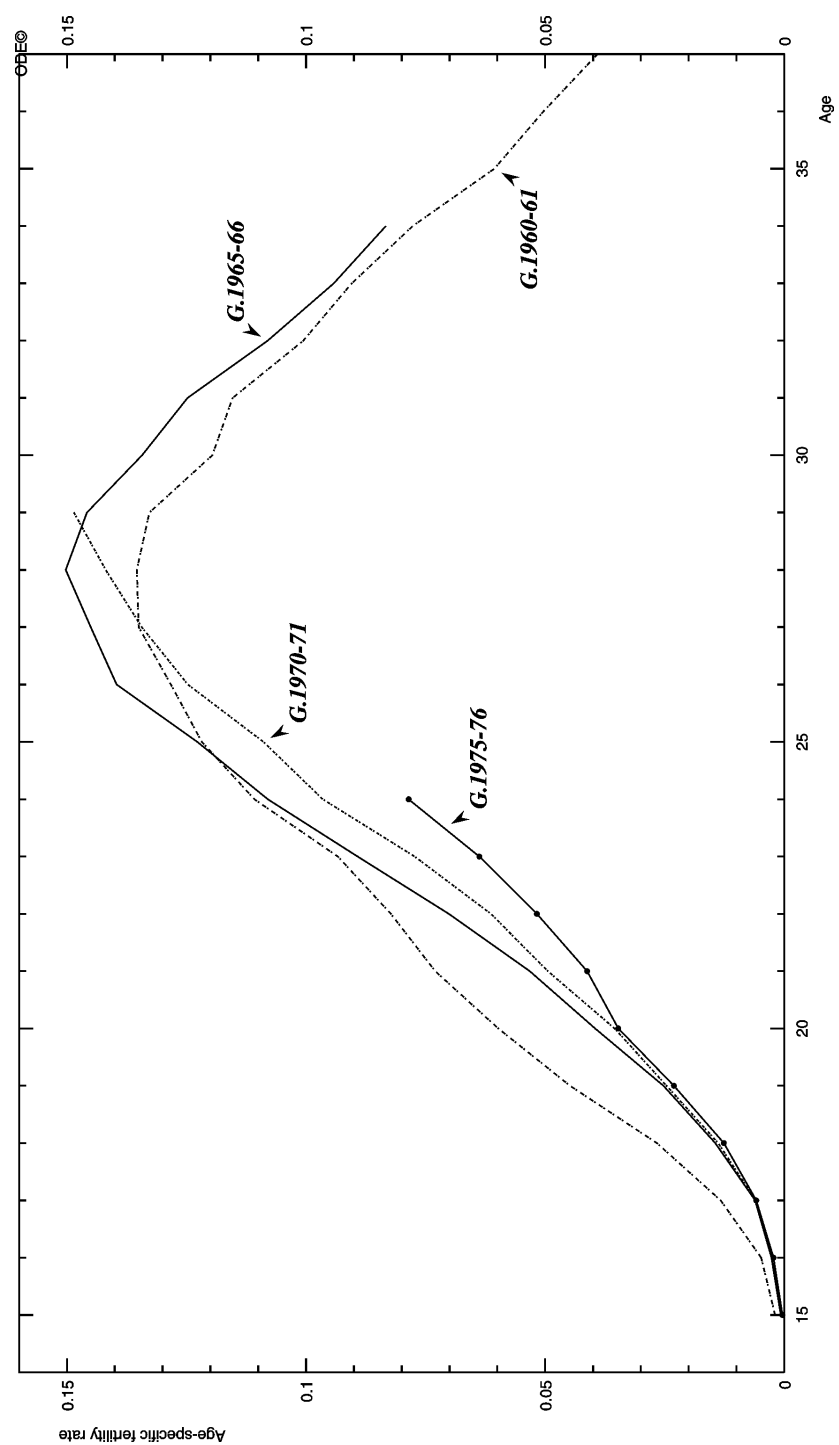




\section{Appendix 2 - FINLAND}

The fertility transition in Finland started around 1910, prior to which known data indicate a stable total period fertility rate (TPFR) of almost 5 children per woman for at least half a century (Chesnais 1992). Within two decades fertility declined to below the replacement level, the TPFR was 2.3 in the year 1933. Toward the end of the 1930s fertility increased somewhat, and the trend during the Second World War was rather erratic. Immediately following the war Finland experienced a distinct baby boom with a peak TPFR of around 3.4 between 1946 and 1950. Thereafter a prolonged decline set in which was at first moderate -- through 1963 -- and then quite steep between that year and 1973 when the TPFR hit 1.5 children per woman. Since then the TPFR has been quite stable fluctuating within a range of 1.60 to 1.85 . In 1998 it was 1.7 children per woman (Fig. F-1).

Finland was the least industrialized of the Scandinavian countries after the Second World War. Roughly half of the active labor force was engaged in agriculture and forestry. Since then the economy has progressed and changed considerably so that the Finns have become as affluent as their neighbors. In 1998 GDP per capita in comparable PPP (purchasing power parity) was estimated at $\$ 20,100$ compared to $\$ 19,700$ in Sweden, $\$ 23,300$ in Denmark, and $\$ 24,700$ in Norway. The largest proportion of the gross domestic product is produced in the service sector, over 60 per cent. In the late $1990 \mathrm{~s}$ about 50 per cent of men and 80 per cent of women were employed in the service sector. Women's labor force participation, 74 per cent in 1994, was almost equal to that of men and the majority of women were in full-time jobs. Such high female labor force participation is in part due to the apparent need for two incomes in a household to cover costs of mortgages as even low income families tend to own their living quarters. On the other hand, a comprehensive day care system enables women with small children to work full-time (Nikander 1998).

The population is healthy and well educated. Life expectancy at birth for women in 1998 was almost 81 years and the infant mortality rate was less than 4 deaths per 1000 live births. Over 15 per cent of the population has a university level education. In the mid-1990s slightly more women than men were studying at the university level. Ethnically and culturally Finland has a very homogeneous population. Ninety three per cent are ethnic Finns and 6 per cent Swedes, with practically no foreign-born people. Immigration is very small. Over 85 per cent belong to the Lutheran church, however, a rapid process of secularization appears to be under way.

Finland does not have a distinctly defined population policy and there have been no efforts to influence fertility. Social and family policies, however, favor families with children. Parents of small children are given the opportunity to care for them at home through a generous system of leaves and allowances. This is combined with the 
obligation of local municipalities to provide quality day care facilities for all children under 7 years of age (Nikander 1998).

The total cohort fertility rate (TCFR) was around 2.6 children per woman for the generations born in the early 1920s (Figs. F-1 and F-2). A considerable decline of the TCFR started with these birth cohorts. The generations born in the late 1930s experienced replacement level fertility and those of the late 1940s TCFRs of below 1.9 children per woman. The cohorts of the 1950s had slightly higher TCFRs with the reliable estimate for the women born in 1960-61 being about 1.95, but thereafter it appears that a slight decline is again setting in.

A detailed analysis of the rapid decline of cohort fertility between the generations of the early 1920s and those of the late 1940s, and then the stabilization around 1.9 through the cohorts of the early 1960s, reveals considerable changes in the lifetime age patterns of fertility of different birth cohorts.

The generations born around 1930 had relatively high fertility at all ages with a peak in their mid-twenties (Fig. F-3). The subsequent decline of cohort fertility was brought about by a considerable reduction in fertility mainly when women were in their thirties. The drop in fertility of the generations born in the late 1930s compared to those 10 years older was over 40 per cent for each single year age group between the ages of 29 and 38. The 1940-41 birth cohort had almost 0.5 children less than the 1930-31 cohort between the ages of 23 and 40 (Table F-1). This was slightly offset by higher fertility at the younger ages. The net result was a TCFR smaller by 0.445 children per woman.

Table F-1: $\quad$ Fertility deficits and surpluses comparing birth cohorts, Finland, cohorts 1930-31, 1940-41, 1950-51 and 1960-61

\begin{tabular}{lllllll}
\hline & \multicolumn{2}{l}{$\begin{array}{l}\text { Cohort 1930-31 and } \\
1940-41\end{array}$} & \multicolumn{2}{l}{$\begin{array}{l}\text { Cohort 1940-41 and } \\
1950-51\end{array}$} & \multicolumn{2}{l}{$\begin{array}{l}\text { Cohort 1950-51 and } \\
1960-61\end{array}$} \\
\cline { 2 - 7 } Fertility & $\begin{array}{l}\text { Age } \\
\text { group }\end{array}$ & $\begin{array}{l}\text { Number of } \\
\text { children }\end{array}$ & $\begin{array}{l}\text { Age } \\
\text { group }\end{array}$ & $\begin{array}{l}\text { Number of } \\
\text { children }\end{array}$ & $\begin{array}{l}\text { Age } \\
\text { group }\end{array}$ & $\begin{array}{l}\text { Number of } \\
\text { children }\end{array}$ \\
\hline Deficit & $23-40$ & -0.486 & $19-27$ & -0.324 & $15-26$ & -0.185 \\
& $42-49$ & -0.001 & & & & \\
Surplus & $15-22$ & +0.040 & $15-18$ & +0.021 & $27-49^{\mathrm{a}}$ & +0.272 \\
& $41-43$ & +0.002 & $28-49$ & +0.154 & & +0.087 \\
\multicolumn{2}{l}{ Total } & -0.445 & & -0.149 & &
\end{tabular}

The generations born during the 1940s gradually adopted different lifetime patterns of childbearing. The difference is evident in the comparison of the age patterns of fertility between the 1940-41 and the 1950-51 birth cohorts (Fig. F-3). The latter generation had 
considerably lower fertility during the peak childbearing years of 20 to 25 , i.e. these women postponed some of their childbearing until later. Between the ages of 19 and 27 the 1950-51 cohort had a comparative deficit of over 0.3 children per woman. Almost half of that deficit was then realized after age 28 (Table F-1), for the most part when these women were in their early thirties. On balance the 1950-51 cohort did have less children than the one ten years older.

The postponement of childbearing was even more pronounced among the cohorts born during the 1950s. Fertility of these women when they were young was much lower than in previous generations. The peak of childbearing shifted from age 25 for the 1950-51 generation to the ages 27-29 in the 1960-61 cohort. Between the ages of 17 and 20 fertility of the 1960-61 birth cohort was about 40 per cent below that of the 1950-51 cohort, however, starting with age 29 and into their late thirties fertility of the 1960-61 cohort was by more than 30 per cent higher compared to those ten years older. As a result the 1960-61 generation more than equaled the completed cohort fertility of the 1950-51 cohort and had 0.087 children more than the older generation (Table F-1). In other words, women of the 1960-61 birth cohort when in their late twenties and thirties caught up in full with the generation ten years older. These women did eventually have all the children they postponed when they were young. This is also evident in Fig. F-2. Note the narrowing of the distance of the curves between the ages of 15 and 25, for instance, for the 1960-61 birth cohort compared to earlier ones, and then the broadening of the distance between the curves of ages 25 and 35 .

Fig. F-4 illustrates how each subsequent cohort of the 1950s through those of the 1970s, in comparison to previous ones, tends to postpone its births until later in the reproductive period. The curves of the differences between the cumulated cohort fertility rates for the generations of 1955-56 and even of 1960-61 initially decline until they reach a trough at the ages 26 to 27 . These curves subsequently climb and eventually cross and then rise above the base line of the 1950-51 cohort. This indicates that the younger cohorts made up all the births they postponed up to their mid-twenties, and that their total cohort fertility rates will be higher than the base line, even though only marginally.

The pronounced changes in the age patterns of fertility are also expressed in the notable changes of the average age of childbearing over time and between generations (Fig. F-5). This age was 26.5 for the 1940-41 birth cohort and it will be around 29 for the generations born in the early 1960s.

The data available for the cohorts which are still at the beginning or in the middle of their childbearing years do indicate a decline in cohort fertility in the future (Table F2 and Figs. F-4 and F-6). Given the experience of the birth cohorts of the 1950s which caught up with the fertility of earlier cohorts, it is conceivable that this will also happen with the generations of the 1960s and 1970s. Indeed, the curve for the 1965-66 birth 
cohort shows that after age 26 it turns upward and thus the difference with the 1950-51 base line diminishes (Fig F-4). The last four columns in Table F-2 indicate that the differences between the cumulated fertility diminish with increasing age of the respective cohort. The difference between the cumulated cohort fertility rate (CCFR) of the 1965-66 generation and the one 10 years older at age 21 was 43 per cent, at age 26 it was 22 per cent and by age 31 only 7 per cent. This is an indication that the catching up process is in progress. At the same time, note in the rows for the respective ages in Table F-2 the CCFR values for each successive cohort are declining. At age 26 the CCFR for the 1970-71 generation is 0.638 compared to 0.761 for the $1960-61$ cohort. This implies that the 1970-71 generation has a larger amount of catching up ahead of it in absolute terms.

Table F-2: $\quad$ Cumulated fertility rates at specified ages and relative changes compared to birth cohorts 10 years older, Finland, birth cohorts 1960-61, 1965-66, 1970-71 and 1975-76.

\begin{tabular}{lllllllll}
\hline & \multicolumn{3}{c}{ Cumulated fertility rate of birth cohort } & \multicolumn{3}{l}{$\begin{array}{l}\text { Change of CCFR compared to cohort } \\
\text { ten years older (in per cent) }\end{array}$} \\
\cline { 2 - 9 } Age & $1960-$ & $1965-$ & $1970-$ & $1975-$ & $1960-$ & $1965-$ & $1970-$ & $1975-$ \\
& 1961 & 1966 & 1971 & 1976 & 1961 & 1966 & 1971 & 1976 \\
\hline 36 & 1.795 & n.a. & n.a. & n.a. & +3 & n.a. & n.a. & n.a. \\
31 & 1.407 & 1.334 & n.a. & n.a. & -0.0 & -7 & n.a. & n.a. \\
26 & 0.761 & 0.679 & 0.638 & n.a. & -20 & -22 & -16 & n.a. \\
21 & 0.236 & 0.170 & 0.162 & 0.140 & -33 & -43 & -31 & -17 \\
\hline
\end{tabular}

For Finland we can conduct a detailed analysis of cohort fertility by birth order, parity progression, parity distribution and childlessness.

The decline of completed cohort fertility from the generations of the $1920 \mathrm{~s}$ to those of the mid-1940s was due mainly to the decline of higher order births, i.e. of birth order 3 and above (Figure F-7). Second order births did not decline for the birth cohorts of the 1920s but did display a relatively mild decline from the birth cohorts of the late 1930 s to those of the late 1940s. First order births were relatively stable through the cohorts of the mid-1940s with around 90 percent of all women having at least one child.

The stable total cohort fertility rates of the generations of the late 1940s and the 1950s were the result of countervailing trends in birth order. First children were declining but a larger proportion of those women who had born a first child was having second and third children. The parity progression ratios from parity zero to one (PP0) was declining whereas particularly the parity progression ratios from the first to the second (PP1) and also from the second to the third (PP2) were increasing. The increase in the parity progression ratio from the first to the second birth was impressive. In the 
1946-47 birth cohort 67 percent of women with a first birth went on to have a second one, whereas among women of the 1956-57 cohort the estimate was that 78 percent did so (Figure F-8). There was also a slight increase in the parity progression ratio from second to third birth.

These changes were reflected in the parity distribution of women (Figure F-9). In the long run, i.e. comparing the birth cohorts of the mid-1920s with those of the mid1950 s, there was a sharp decline in families with four or more children, from about 25 percent of the total to below 10 percent. Women with no more than one child at first increased. These reached a peak with the birth cohorts of the mid-1940s and have since declined. The largest increase was among women of parity 2 . These increased from 23 percent among women of the birth cohorts of the mid-1920s to 39 percent among the women of the mid-1940s. Since then they have been mildly declining. The proportions of childless women have also been on the rise among the younger birth cohorts. Women of parity zero were around 10 percent through the birth cohorts of the late 1940s. The estimates for subsequent cohorts are on the rise. Among women of the 1956-57 cohort probably 16 percent will remain childless.

Judging by the trends in childlessness at different ages of the cohorts born in the 1960s (Figure F-10, in which all data are taken from registration), it would appear that the proportion of childless women in Finland is likely to continue to increase. For instance, among woman of age 30 the proportion childless of the 1940-41 birth cohort was 20 percent and for the 1967-68 cohort it had more than doubled to 43 percent. 
Figure F-1: Total period fertility rate, Finland, 1950-2000, and total cohort fertility rate in Finish birth cohorts, 1919-1965 lagged by the average age at childbearing

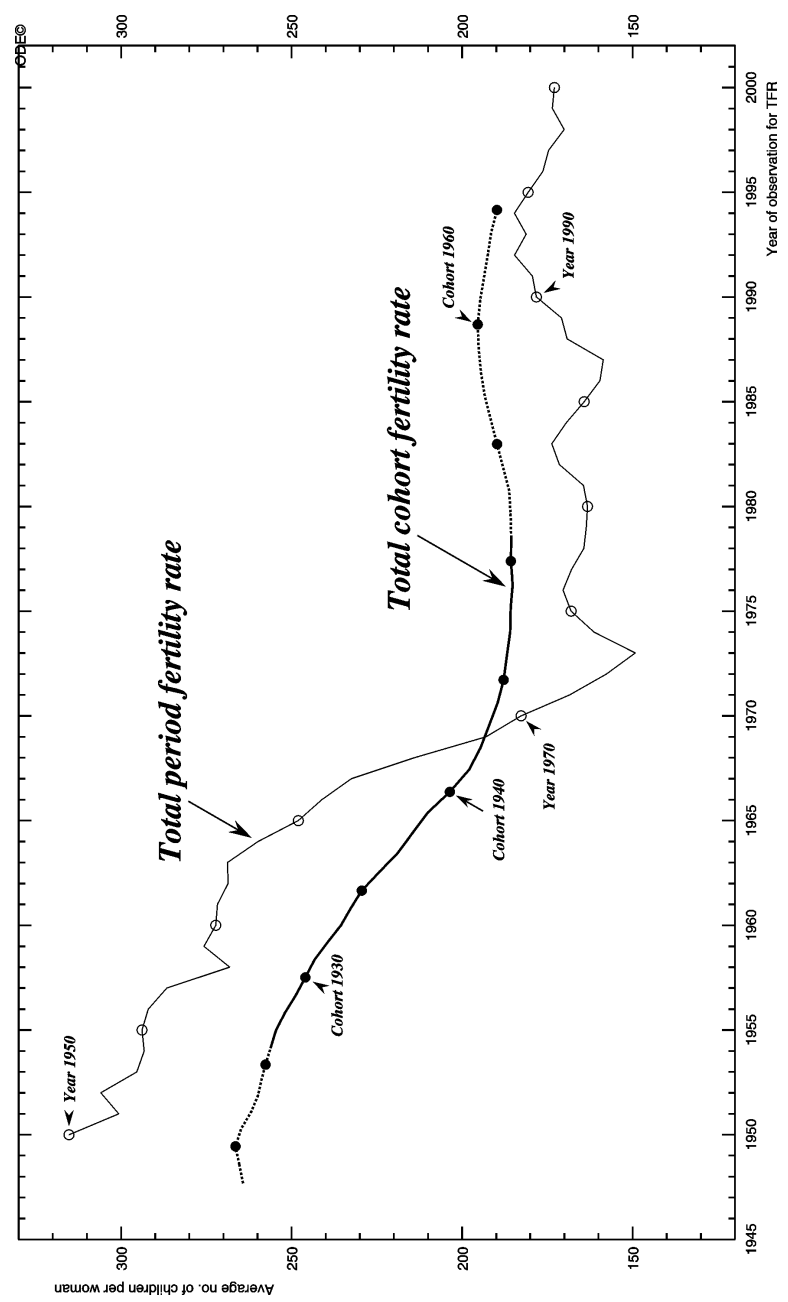

Note: Dotted lines indicate that a minor proportion of the respective TCFRs is based on estimates 
Figure F-2: Cumulated cohort fertility at specified ages, Finland, birth cohorts $1927-$ 1975

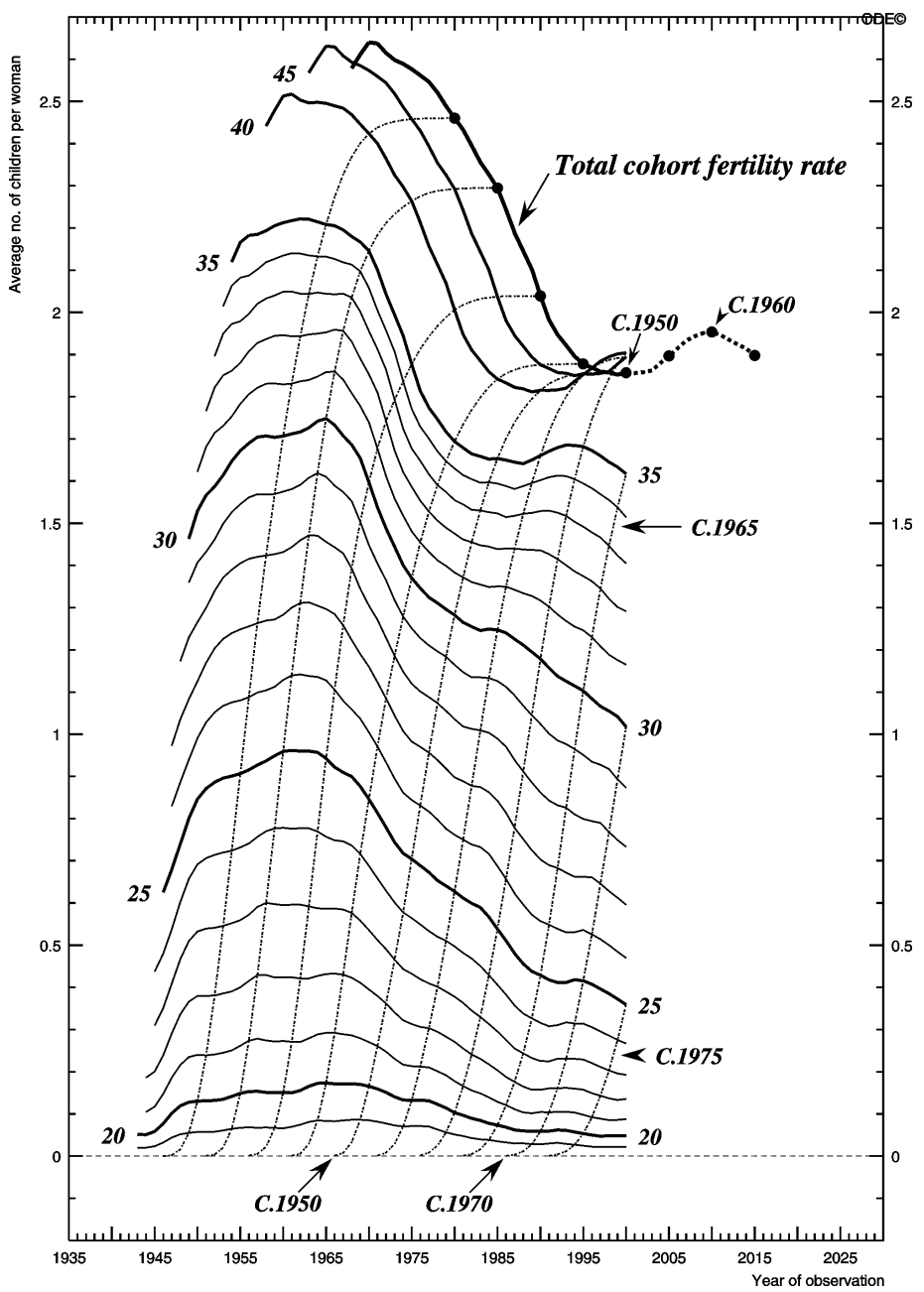

Note: The part of the TCFR line which is dotted indicates that a minor proportion of the TCFR is based on estimates 
Demographic Research - Volume 5, Article 5

Figure F-3: Age-specific fertility rates, Finland, birth cohorts 1930-31, 1940-41, 1950-51 and 1960-61

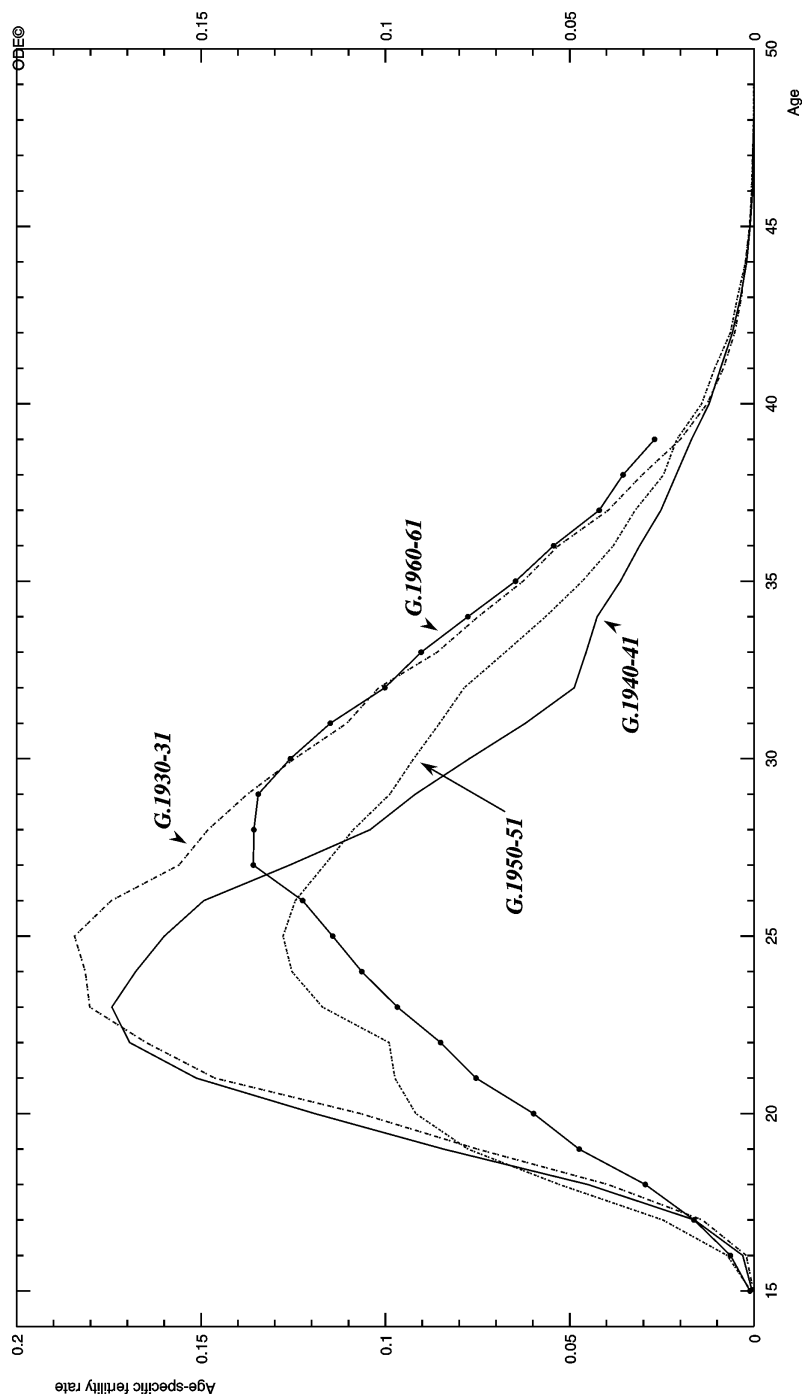


Demographic Research - Volume 5, Article 5

Figure F-4: Differences in cumulative age-specific cohort fertility rates between base and subsequent cohorts: Finland, women born in 1950-51 (base), 195556, 1960-61, 1965-66, 1970-71 and 1975-76

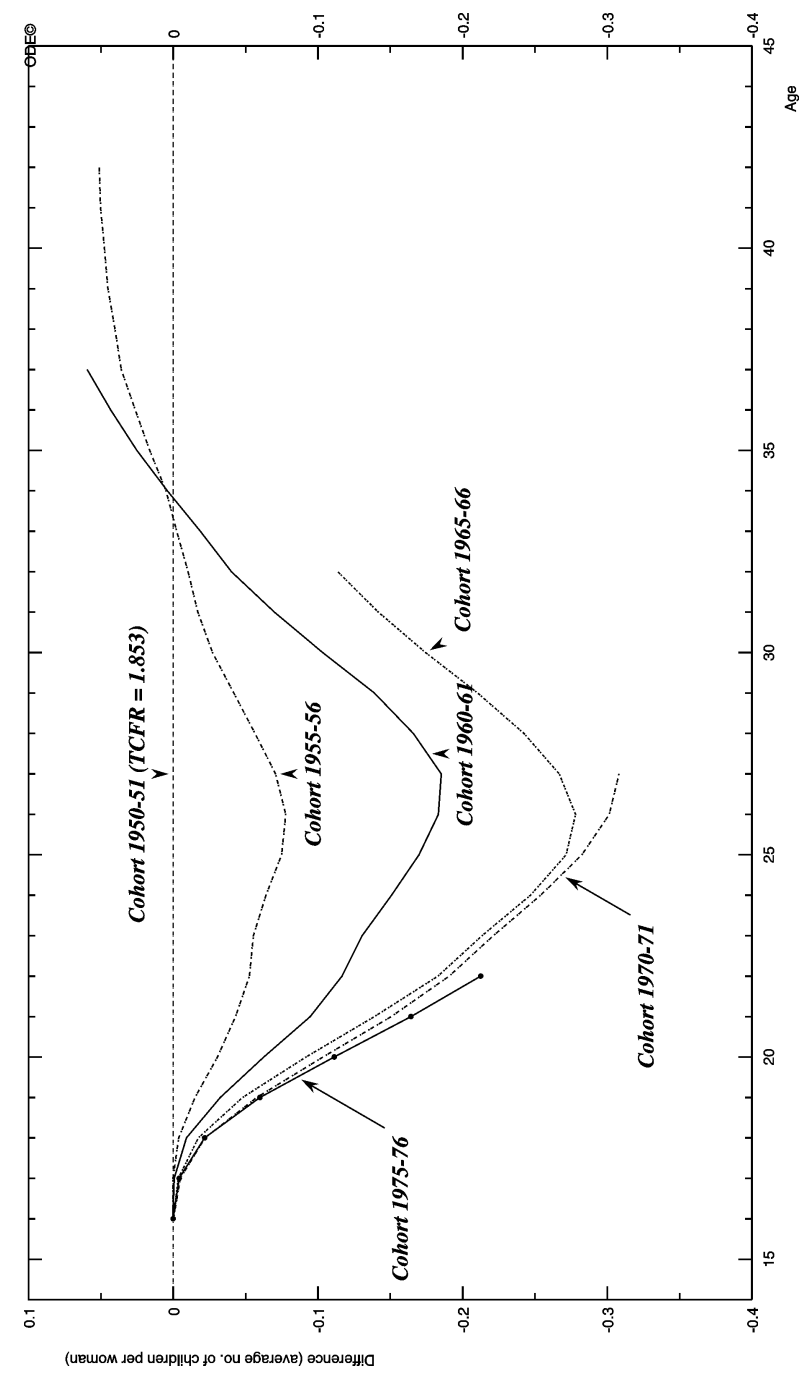


Figure F-5: Period average age of childbearing, 1941-2000, cohort average age of childbearing, birth cohorts 1923-1965, Finland

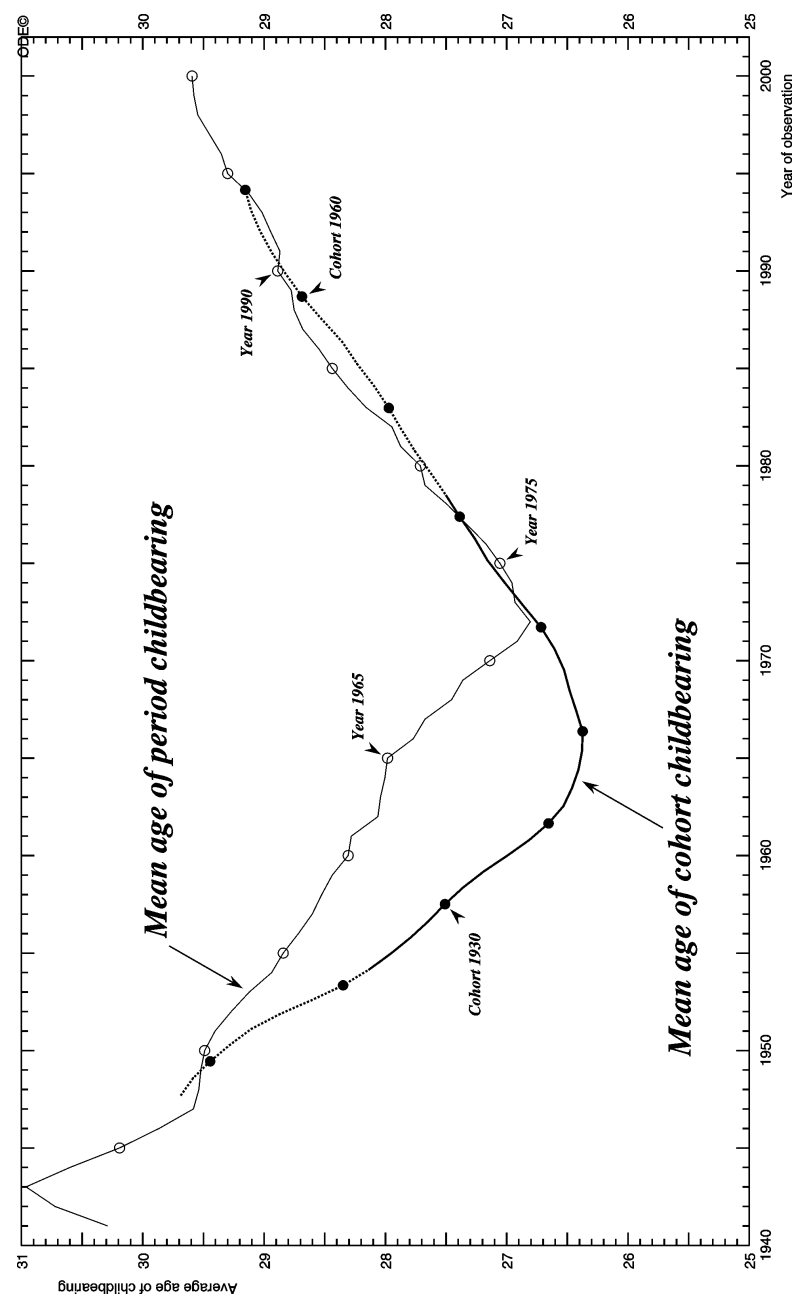

Note: The part of the "mean age of cohort childbearing" line which is dotted indicates that a minor proportion of the respective agespecific rates are based on estimates 
Demographic Research - Volume 5, Article 5

Figure F-6: Age-specific fertility rates, Finland, birth cohorts 1960-61, 1965-66, 1970-71 and 1975-76

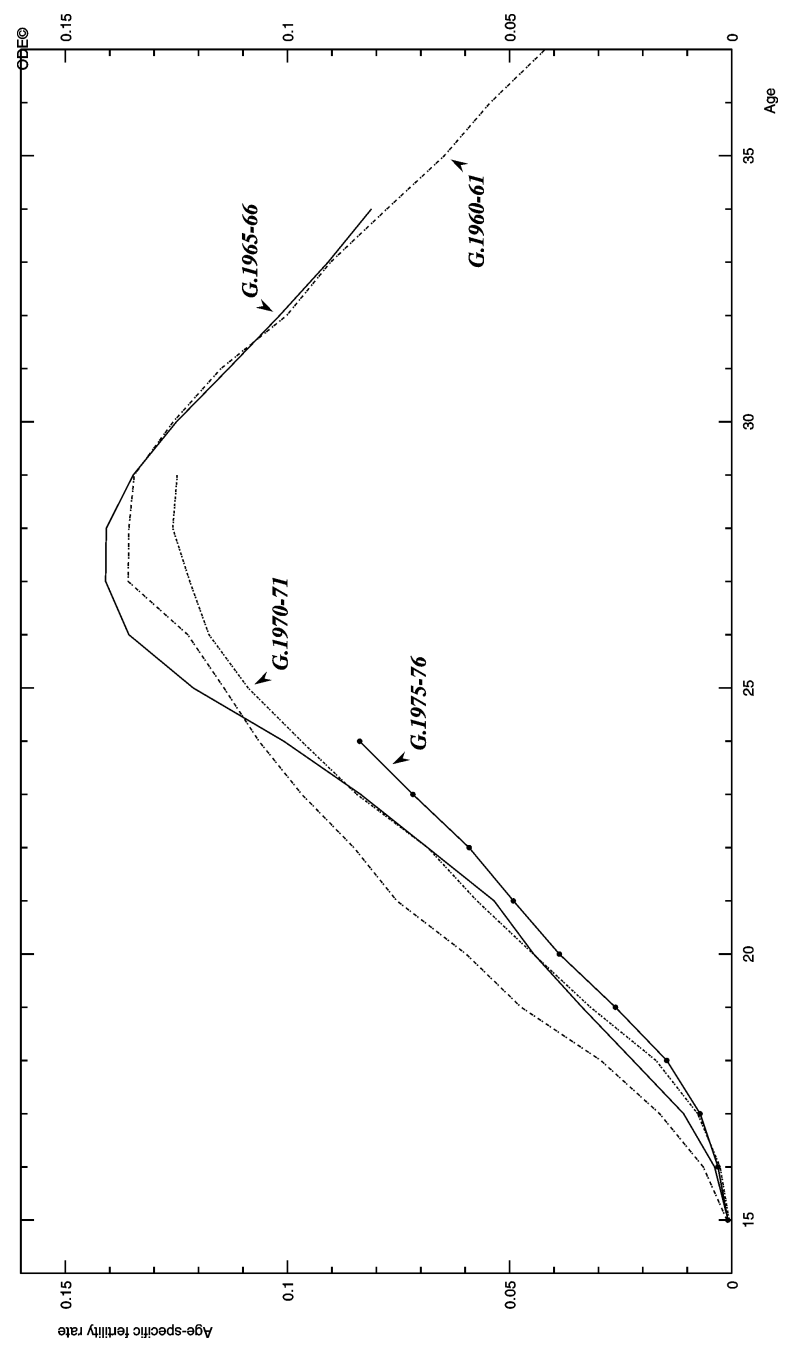


Figure F-7: Total cohort fertility rates by biological birth order, Finland, birth cohorts 1925-26 to 1966-67

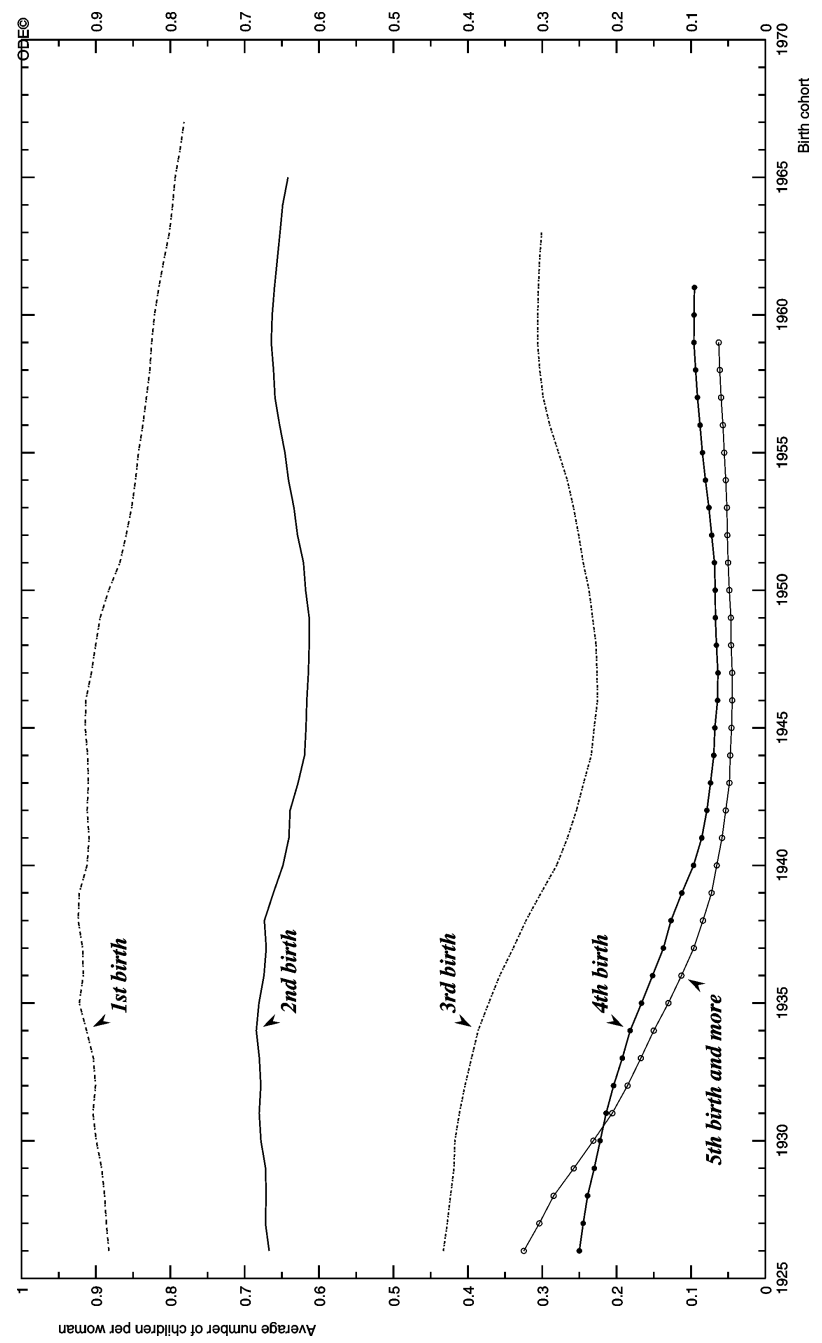

Note: Years on $\mathrm{x}$-axis refer to second half of birth cohort 
Demographic Research - Volume 5, Article 5

Figure F-8: Parity progression ratios, Finland, birth cohorts 1925-26 to 1961-62

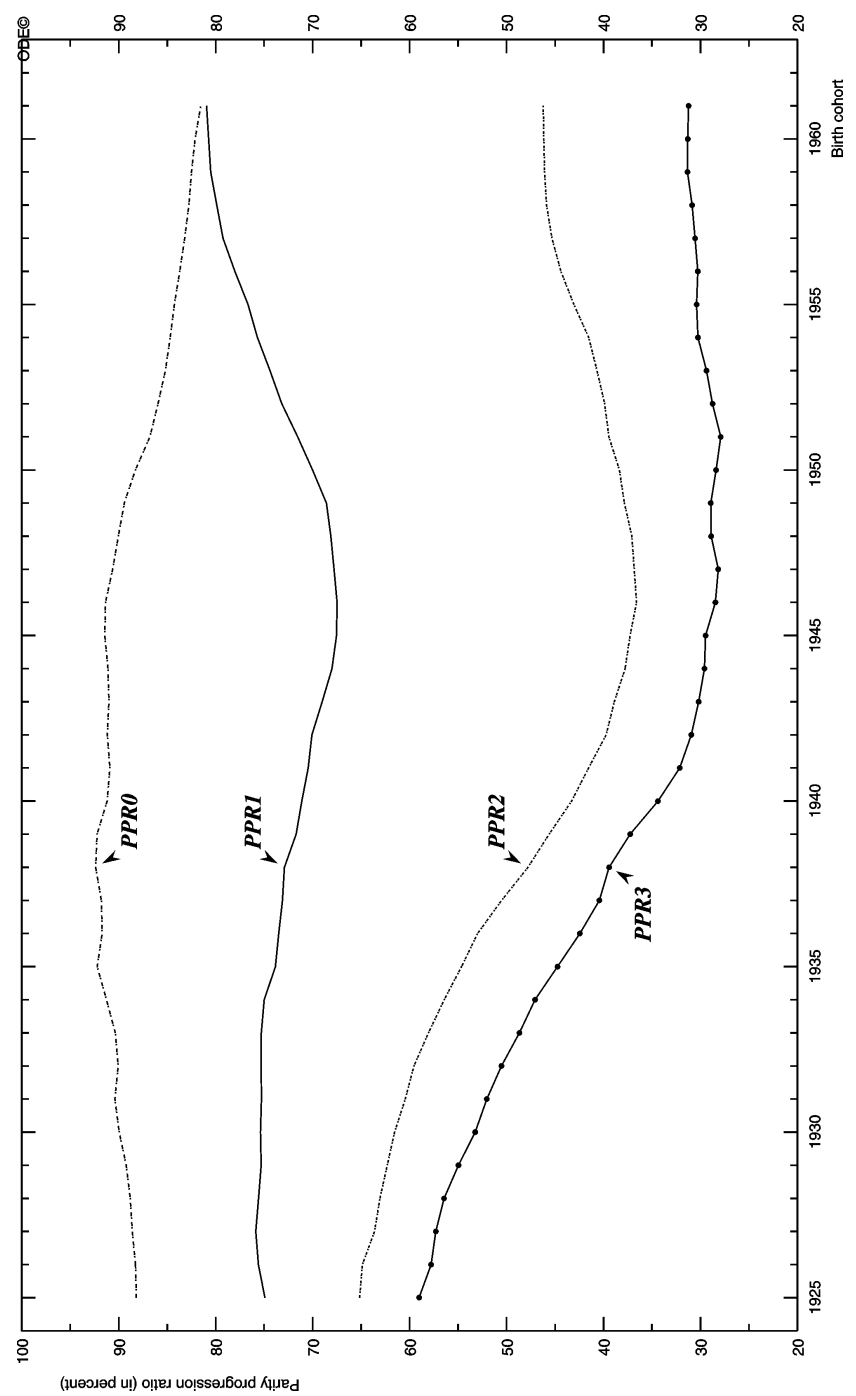

Note: Years on $\mathrm{x}$-axis refer to first half of birth cohort 
Demographic Research - Volume 5, Article 5

Figure F-9: Parity distribution of completed fertility, Finland, birth cohorts 1925-26 to 1958-59 (in percent)

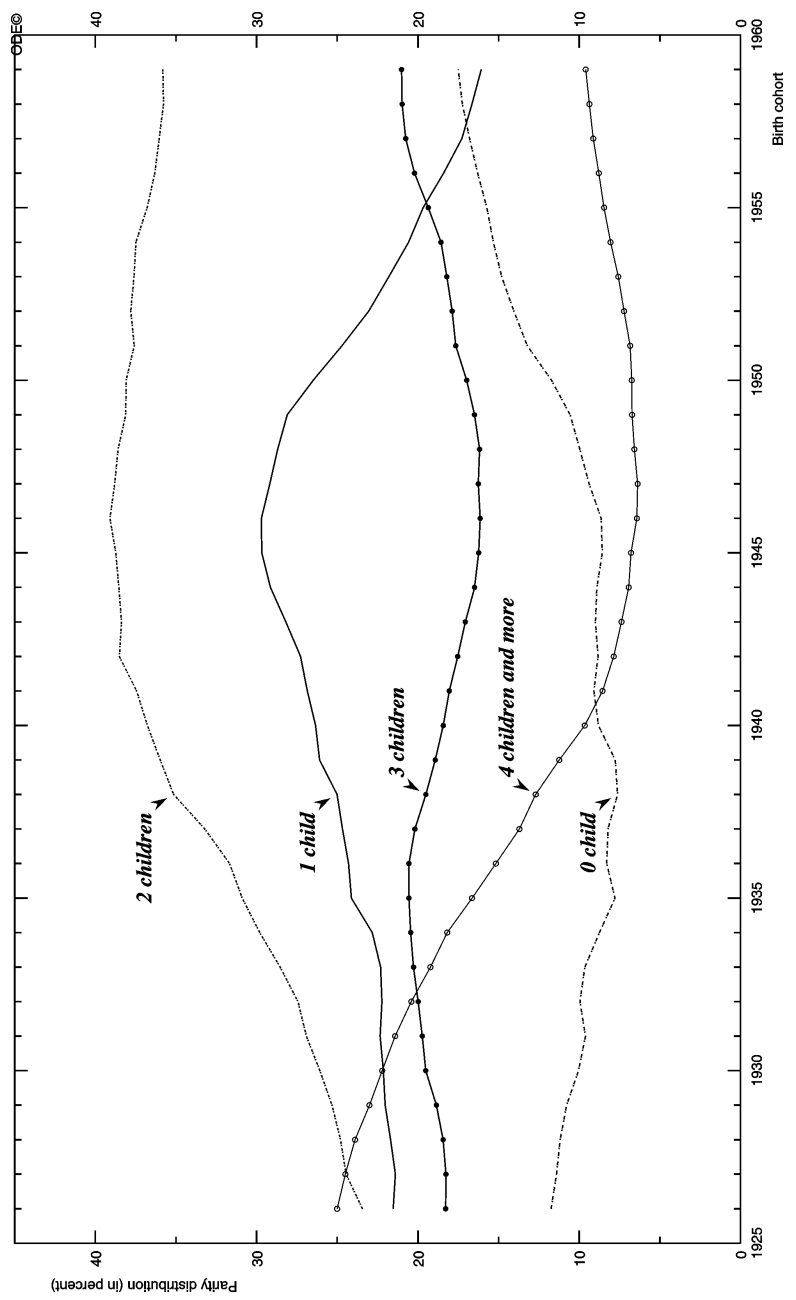

Note: Years on $\mathrm{x}$-axis refer to second half of birth cohort 
Demographic Research - Volume 5, Article 5

Figure F-10: Proportions of childless women, selected ages, Finland, birth cohorts 1925-26 to 1979-80

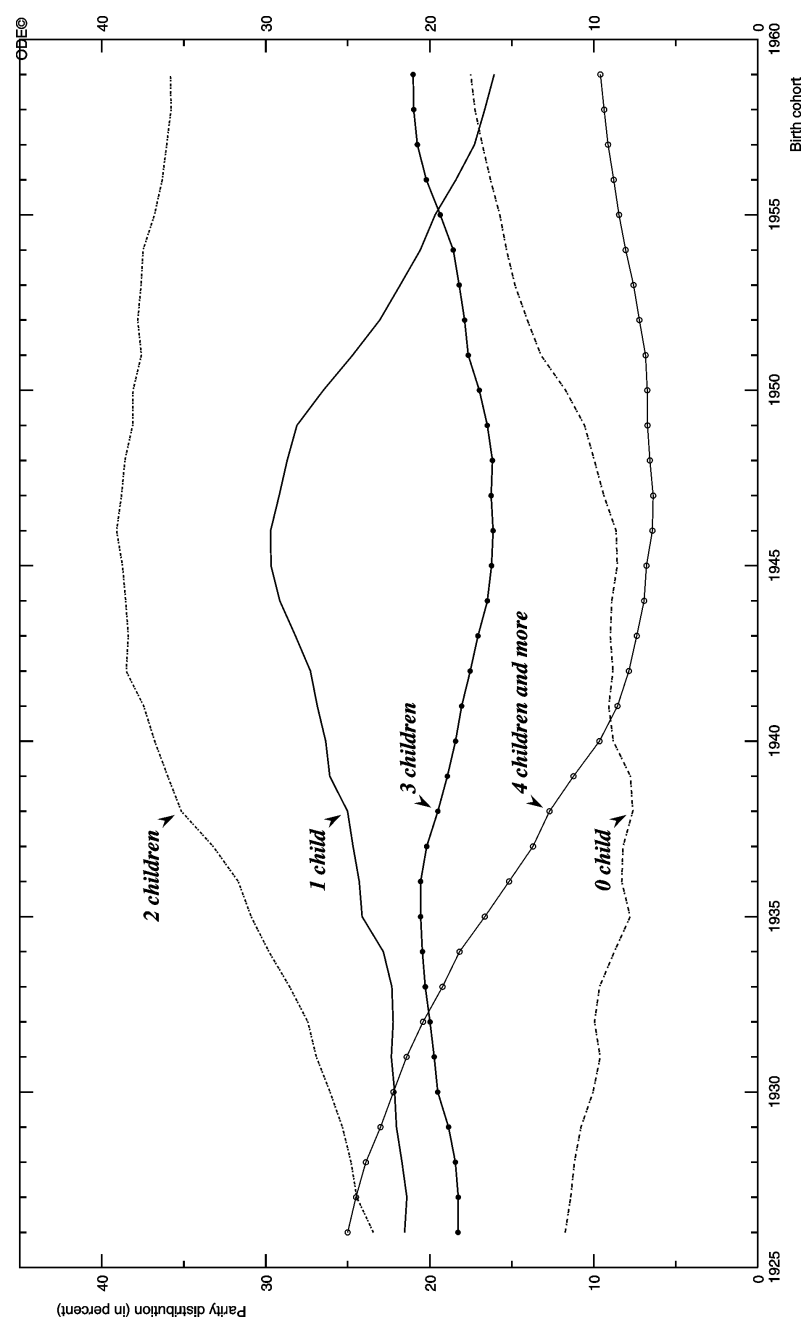

Note: Years on $\mathrm{x}$-axis refer to first half of birth cohort 


\section{Appendix 3 - NORWAY}

The Norwegian population experienced a rapid fertility decline starting late in the $19^{\text {th }}$ century into the 1920s and 1930s. The total period fertility rate (TPFR) fell from 4.5 children per woman in the 1890 s to 2.2 around 1930 and was considerably below the replacement level throughout the 1930s. There was a well-defined post-war recovery of fertility, a baby boom, with a TPFR peak in 1964 of 3.0 children per woman (Fig. N-1). This was followed by a precipitous decline reaching a trough in the late 1970s and early 1980s at the level of about 1.7. The TPFR increased slightly in the late 1980s to reach 1.9 in 1990 and has since declined almost imperceptibly to 1.8 in 1998. This is moderately above the median for western low fertility countries.

During the second half of the $20^{\text {th }}$ century Norway's population lived through many of the common social and economic transformations of industrialized and postindustrial societies. Women's participation in the labor force was continuously increasing as was educational attainment. Employment was shifting into the service sector; about 85 percent of employed women in 1990 were in that sector. Norway's economy was less vulnerable to recession pressure because Norway developed its own oil production. Compared to other European countries, Norway continued to be homogeneous in terms of ethnic and religious composition, and a certain secularization process appeared to be afoot. An unequivocal betterment in living standards and housing conditions was transpiring (Noack and Ostby 1996).

While Norway never had an explicit population policy, it did have policies that affected fertility behavior. Legislation concerning families and children as well as the equality of opportunity for men and women are believed to have contributed to the modest fertility increase of the late 1980s. Parental leave, for instance, was gradually increased so that couples in the mid-1990s had the right to either 42 weeks of leave with full salary or 52 weeks with 80 percent compensation (Noack and Ostby 1996).

The trend of the total cohort fertility rate (TCFR) for women born since the mid1920s at first showed an increase from 2.3 children per woman for the 1923-24 birth cohort to 2.6 for the 1933-34 generation (Figure N-1). This was followed by a gradual decline with cohort replacement fertility being reached by generations of the late 1940s. For the generations that followed cohort fertility was moving within an extremely narrow band of slightly below replacement fertility estimated to be between 2.047 and 2.085 children per woman. The estimate of the third decimal place might be questionable but the general direction of change and the level of weak replacement fertility are dependable. Cohorts born in the late 1950s and early 1960s all will apparently have TCFRs of 2.08. It appears that cohort fertility for these cohorts has leveled off. 
While the TCFR trend appeared to be smooth, the age patterns of childbearing were remarkably different from one cohort to the next (Figures N-2 and N-3 and Table $\mathrm{N}-1$ ). Completed cohort fertility of the 1930-31 and the 1940-41 generations were quite similar, 2.51 and 2.43 respectively. Yet there was a considerable fertility increase among young women born, for instance, in 1940-41 compared to those of the 1930-31 generation. The age curve of childbearing moved substantially to the left. Between the ages of 16 and 20 fertility was 54 to 98 percent higher for individual ages. On the other hand, once the women of the 1940-41 generation got into their thirties and forties they were having considerably less children than the generation born ten years earlier. Between the ages of 34 and 45 they were having 50 to 60 percent less children. In absolute terms, the 1940-41 cohort compared to the 1930-31 cohort had 0.330 more children between the ages of 16 and 26, and 0.411 less children per woman between 27 and 45 years of age (Table N-1).

Table N-1: Fertility deficits and surpluses comparing birth cohorts, Norway, cohorts 1930-31, 1940-41, 1950-51 and 1960-61

\begin{tabular}{lllllll}
\hline \multirow{2}{*}{ Fertility } & \multicolumn{2}{l}{$\begin{array}{l}\text { Cohort 1930-31 and } \\
1940-41\end{array}$} & & $\begin{array}{l}\text { Cohort 1940-41 and } \\
1950-51\end{array}$ & \multicolumn{2}{l}{$\begin{array}{l}\text { Cohort 1950-51 and } \\
1960-61\end{array}$} \\
\cline { 2 - 7 } & $\begin{array}{l}\text { Age } \\
\text { group }\end{array}$ & $\begin{array}{l}\text { Number of } \\
\text { children }\end{array}$ & $\begin{array}{l}\text { Age } \\
\text { group }\end{array}$ & $\begin{array}{l}\text { Number of } \\
\text { children }\end{array}$ & $\begin{array}{l}\text { Age } \\
\text { group }\end{array}$ & $\begin{array}{l}\text { Number of } \\
\text { children }\end{array}$ \\
& & & & & & \\
\hline Deficit & $27-45$ & -0.411 & $20-33$ & -0.399 & $17-25$ & -0.360 \\
Surplus & $16-26$ & +0.330 & $15-19$ & +0.022 & $15-16$ & +0.003 \\
& & $34-45$ & +0.036 & $26-49^{a}$ & +0.356 \\
Total & & -0.081 & & -0.341 & & -0.001 \\
\hline Note: ${ }^{a}$ Includes estimated data for ages $37-49$, which were very small. & & &
\end{tabular}

Among the birth cohorts of the 1940s TCFRs declined from 2.43 for the 1940-41 generation to 2.09 for the 1950-51 generation. It was essentially a decline of fertility while women were in their twenties which brought about this decline (Figures N-2 and $\mathrm{N}-3$ and Table N-1).

The TCFRs of the 1950-51 and the 1960-61 generation were identical, 2.09 children per woman. But a further profound change in the age pattern of childbearing took place, namely a pronounced and genuine shift into the older ages. Up to the age of 25 women in the 1960-61 birth cohort were having much less children than any previous generation; between the ages of 18 and 22 over 40 percent less than the cohort born ten years earlier and the absolute deficit between the ages of 17 to 25 was 0.360 children per woman. On the contrary, when these women were in their thirties they were having many more children than the older generation; between the ages of 34 and 36 the increase was about 70 percent. Between ages 26 and 49 the increase was 0.356 
children per woman. This was one of the rare cases, nonetheless typical for the Nordic countries, that a birth cohort made up for the whole fertility deficit it forwent when it was young. In Figure N-4 note the ascent of the curves for the generations born before 1965 which followed the steep declines. By age 37 the curve for the 1960-61 birth cohort was only slightly below the base line of the 1950-51 cohort. The 1965-66 cohort was following a similar path at a slightly lower level.

What are the childbearing levels and age patterns of the youngest birth cohorts of the late 1960s and 1970s going to be like? For the time being, as of the late 1990s, each successive birth cohort is experiencing lower fertility than the previous one. By age 31 the 1965-66 generation had a cumulated cohort fertility rate of 1.51 , which was seven percent less than the generation born ten years earlier (Figure N-4). By age 26 the 197071 cohort had a CCFR of 0.74 or 18 percent below that of the 10 years older generation. Finally, by age 21 the 1975-76 cohort had a CCFR of 0.17 or 26 percent less than the generation born ten years earlier (Table N-2). Note, however, in the last four columns of the table that the relative differences between the generations are declining with age. This indicates that the tendency for cohorts to make up for the deficits incurred when the cohorts were young continues.

The curves in Figure N-5 illustrate how each successive cohort of the 1960s and 1970 s is postponing more births than any previous cohort. Practically every single agespecific fertility rate is lower than the one of the five years older generation.

These trends are an indication that cohort fertility is likely to decline in the future. Even if these generations make up for their fertility deficits (calculated in comparison to cohorts 10 years older) when they will be older, their completed fertility is likely to be lower than that of the generations born earlier. Note that the cohort born in 1970-71 had a deficit of over 0.5 children per woman by age 27 compared to the 1950-51 cohort (Figure N-4). Women of the $1960 \mathrm{~s}$ and $1970 \mathrm{~s}$ birth cohorts would have to overcompensate for their earlier fertility deficits when they will be in their thirties in order to reach replacement fertility. 
Table N-2: $\quad$ Cumulated cohort fertility rates at specified ages and relative changes compared to birth cohorts 10 years older, Norway, cohorts 1960-61, 1965-66, 1970-71 and 1975-76.

\begin{tabular}{lllllllll}
\hline & \multicolumn{3}{c}{ Cumulated fertility rate of birth cohort } & \multicolumn{4}{c}{$\begin{array}{c}\text { Change of CCFR compared to cohort } \\
\text { ten years older (in per cent) }\end{array}$} \\
\cline { 2 - 9 } Age & $\begin{array}{l}\text { 1960- } \\
\text { 1965- }\end{array}$ & $1970-$ & $1975-$ & $1960-$ & $1965-$ & $1970-$ & $1975-$ \\
& 1961 & 1966 & 1971 & 1976 & 1961 & 1966 & 1971 & 1976 \\
\hline 36 & 1.980 & n.a. & n.a. & n.a. & -2 & n.a. & n.a. & n.a. \\
31 & 1.572 & 1.506 & n.a. & n.a. & -11 & -7 & n.a. & n.a. \\
26 & 0.908 & 0.839 & 0.743 & n.a. & -28 & -21 & -18 & n.a. \\
21 & 0.307 & 0.235 & 0.216 & 0.174 & -40 & -44 & -30 & -26 \\
\hline
\end{tabular}

The meager data on cohort birth order that are at our disposal to date provide limited, but important information (Table N-3). As expected, the proportion of higher order births is becoming smaller for the younger cohorts. By age 40 the 1940 birth cohort had almost one half of all children of order three or higher compared to the 1958 cohort in which only one third of births were of that order. By age 30 with data available for the 1968 cohort there were 12 percent of children of order $3+$ in that cohort, compared to 31 percent in the 1940 cohort. Even though a relatively large proportion of higher order births are borne by women in their thirties and forties the approximate relation between these two birth cohorts is likely to be similar once these cohorts will have concluded their childbearing.

On the other end of the spectrum, there is a clear indication that the proportion of women not having any children is increasing among the younger cohorts (Table N-3). For women at age 40 their proportion increased from 10 to 12 percent between the 1940 and the 1958 birth cohorts. Comparing the 1968 and the 1940 birth cohorts at age 30 there was almost a doubling of the percent of women remaining childless. Considering that women of the younger generations are postponing their childbearing compared to the older generations, it can be surmised that the difference between these two cohorts will diminish by the end of their childbearing periods. But there can be no doubt that there is a trend of increasing proportions of childless women among the younger cohorts in Norway. 
Demographic Research - Volume 5, Article 5

Table N-3: $\quad$ Parity distribution and average number of children by age and birth cohort, Norway, cohorts 1935-1978

\begin{tabular}{rrrrrrrr}
\hline Age & Birth & \multicolumn{9}{c}{ Parity distribution (in percent) } & Average \\
& cohort & 0 & 1 & 2 & 3 & $4+$ & $\begin{array}{r}\text { Averamer of } \\
\text { children }\end{array}$ \\
\hline 20 & 1940 & 79.6 & 16.9 & 3.2 & 0.3 & 0.0 & 0.24 \\
& 1960 & 83.9 & 14.4 & 1.6 & 0.1 & 0.0 & 0.18 \\
& 1978 & 92.5 & 6.8 & 0.7 & 0.0 & 0.0 & 0.08 \\
30 & 1940 & 15.8 & 16.8 & 36.0 & 22.0 & 9.3 & 1.92 \\
& 1960 & 25.9 & 25.1 & 35.1 & 11.7 & 2.2 & 1.39 \\
& 1968 & 30.1 & 26.2 & 31.7 & 10.0 & 2.0 & 1.27 \\
& & & & & & & \\
& 1940 & 9.7 & 10.1 & 33.9 & 29.0 & 17.3 & 2.34 \\
& 1958 & 12.3 & 14.2 & 40.2 & 24.9 & 8.4 & 2.03 \\
\hline
\end{tabular}

Source: Lappegård 2000 
Figure N-1: Total period fertility rate, Norway, 1950-2000, and total cohort fertility rate in Norwegian birth cohorts, 1923-1966 lagged by the average age at childbearing

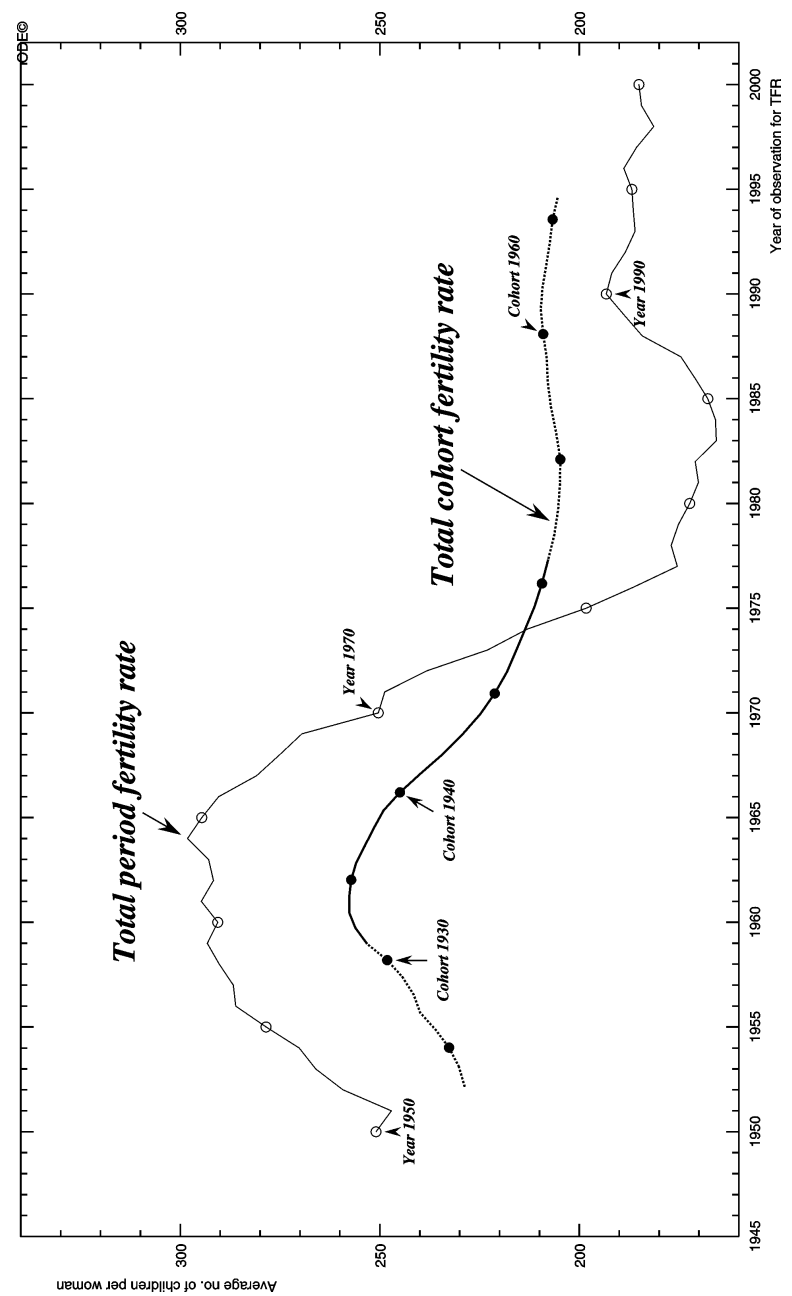

Note: Dotted lines indicate that a minor proportion of the respective TCFRs is based on estimates 
Demographic Research - Volume 5, Article 5

Figure N-2: Age-specific fertility rates, Norway, birth cohorts, 1930-31, 1940-41, 1950-51 and 1960-61

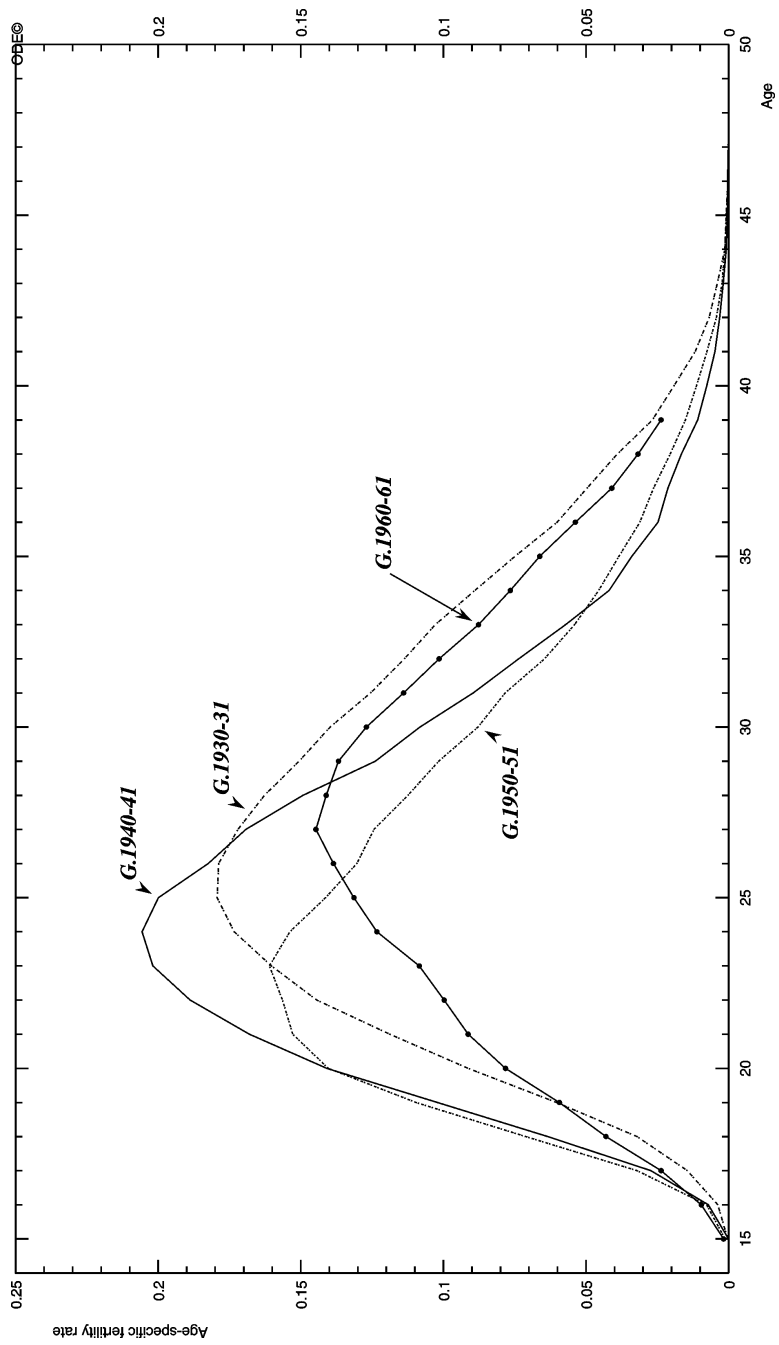


Figure N-3: Cumulated cohort fertility at specified ages, Norway, birth cohorts $1927-$ 1975

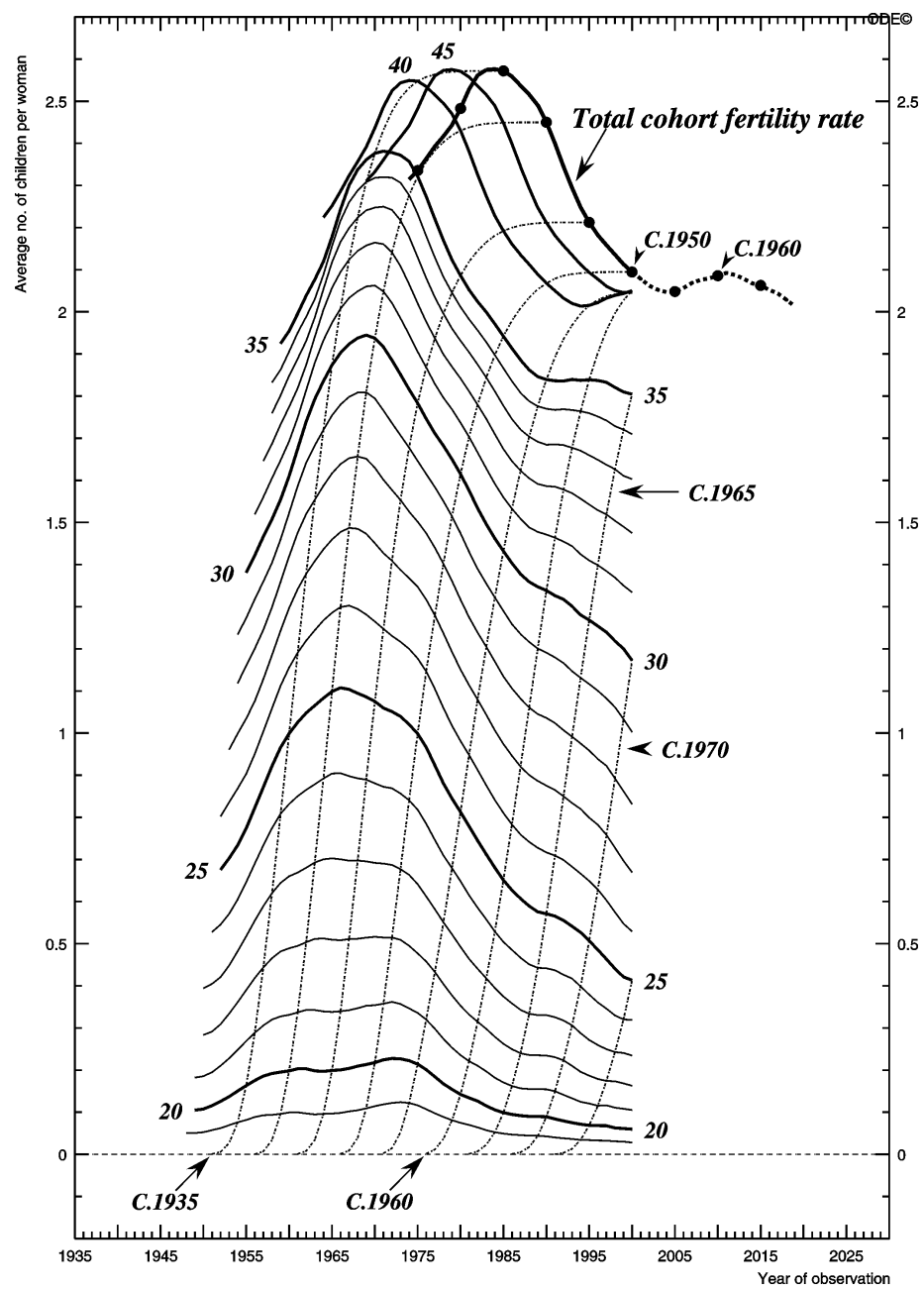

Note: The part of the TCFR line which is dotted indicates that a minor proportion of the TCFR is based on estimates 
Figure N-4: Differences in cumulative age-specific cohort fertility rates between base and subsequent cohorts: Norway, women born in 1950-51 (base), 195556, 1960-61, 1965-66, 1970-71 and 1975-76

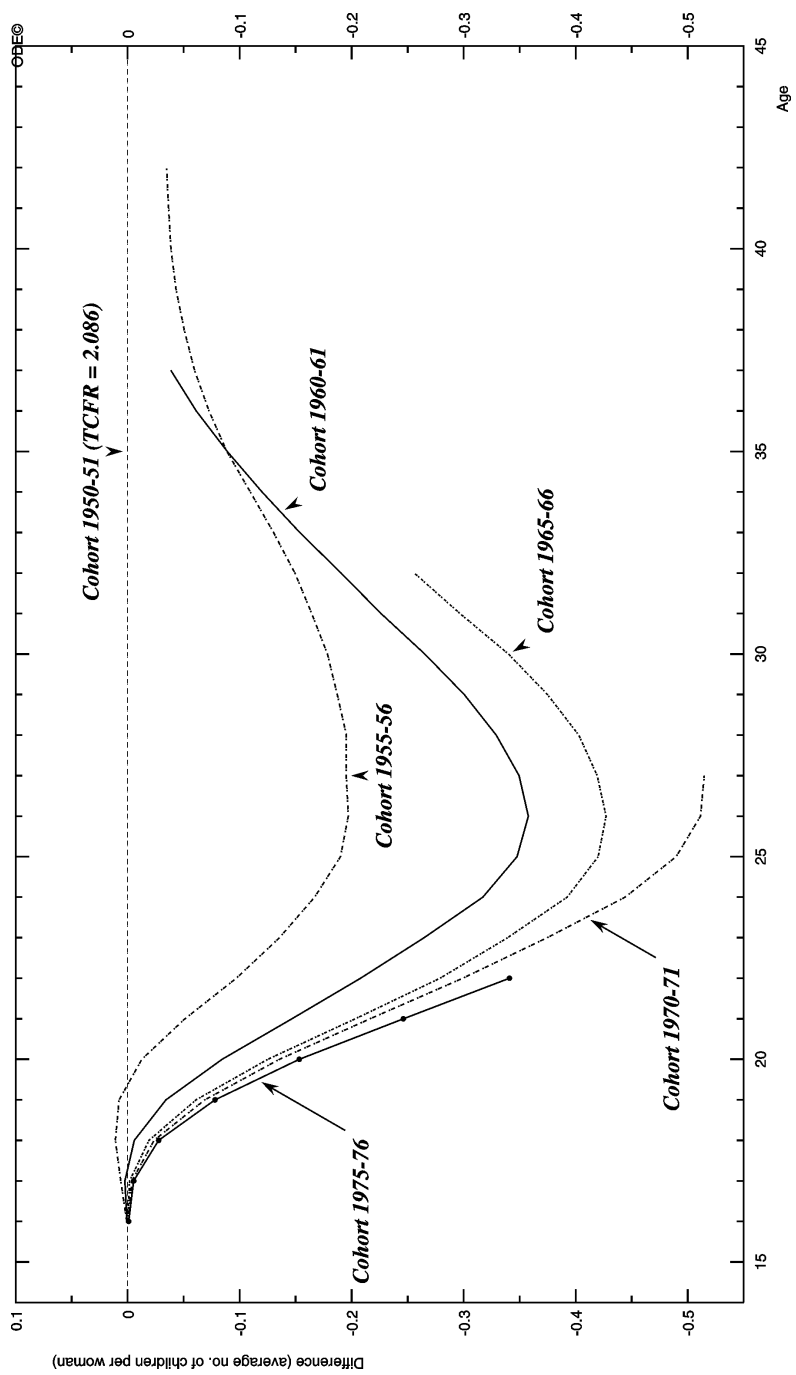


Figure N-5: Age-specific fertility rates, Norway, birth cohorts 1960-61, 1965-66, 1970-71 and 1975-76

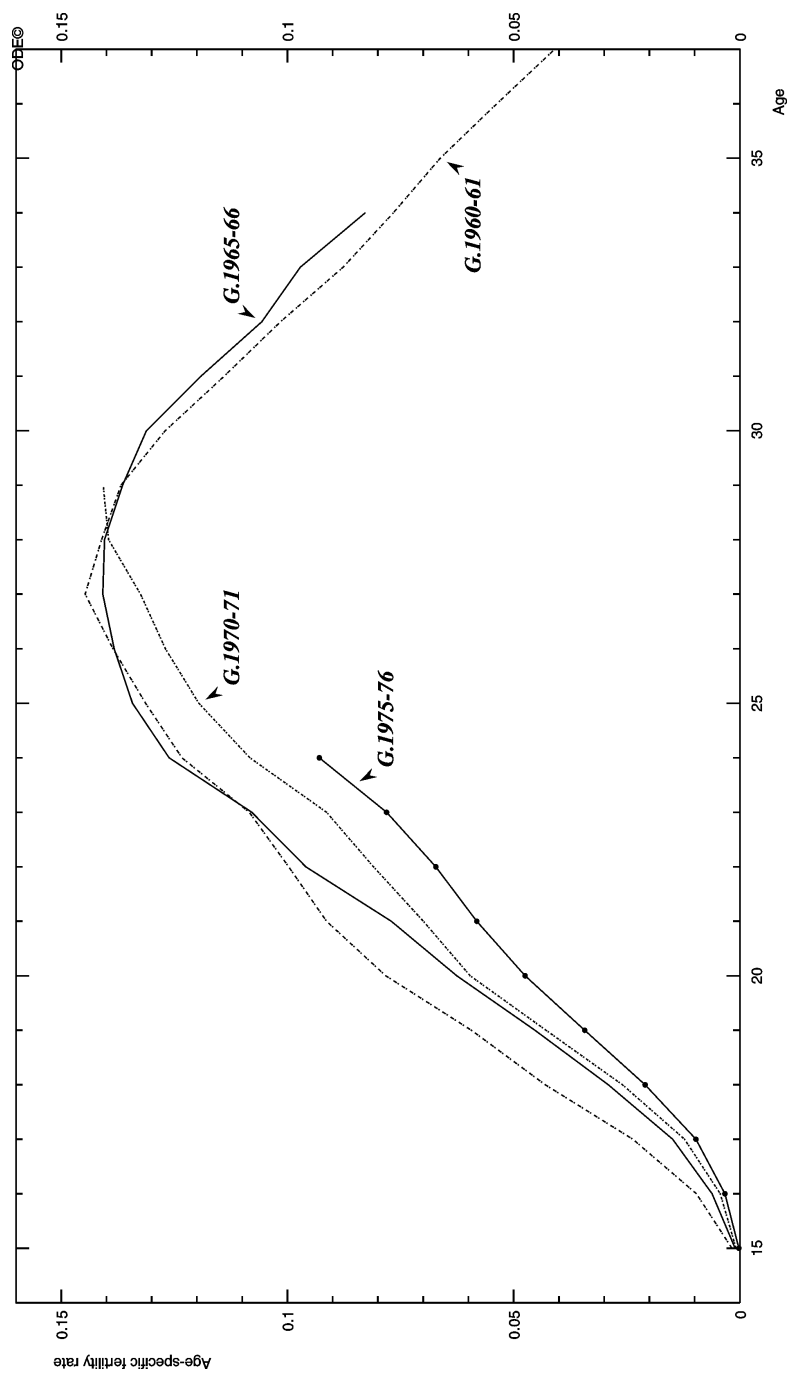




\section{Appendix 4 - SWEDEN}

As in most other European countries, fertility was not very high in pre-industrial Sweden of the $19^{\text {th }}$ century. The fertility transition started from an average total period fertility rate (TPFR) of about 4.5 children per woman in the 1870 s. During the remainder of the $19^{\text {th }}$ and in the first decade of the $20^{\text {th }}$ century the decline was very gradual. It then accelerated and by the mid-1920s, Sweden was among the first countries where fertility reached and fell below replacement. Fertility was very low throughout the 1930s and early 1940s. Sweden's mid-century "baby boom" started earlier than elsewhere in part because Sweden remained a neutral country during the Second World War. A fertility peak was reached in 1944-46 with a TPFR of 2.6 and remained above the replacement level between 2.2 and 2.5 through the mid-1960s (Fig. S-1). Another two-decade long period of below replacement fertility was experienced from the late 1960s through the mid-1980s. The TPFR rose temporarily to 2.1 in 1990 only to decline again through the late 1990s to 1.5 children per woman.

Within a period of one century, Sweden was transformed from an agricultural to an industrial and eventually to a service society. In the $1880 \mathrm{~s}$ three quarters of the population was employed in agriculture. By 1990, sixty per cent of the gross domestic product (GDP) originated in the service sector; 53 per cent of men and 85 per cent of women were employed in this sector. By 1990 the GDP had increased tenfold since the beginning of the century (Granström 1997). Living standards in Sweden have been among the highest in the world since the 1930s. Its GDP per capita expressed in purchasing power parity was almost $\$ 20,000$ in 1998 . While the long-term trend of rising living standards is undeniable, various short-term critical developments occurred and influenced people's wellbeing and behavior.

Sweden was one of the first European countries to change from a country of emigration to one attracting foreigners in significant numbers. Between the middle of the $19^{\text {th }}$ century and the 1930 s almost one and a half million people emigrated to North America. Since then about one million people have immigrated so that by the late 1990s eleven percent of the population was foreign born (Granström 1997).

The population has become very well educated, in particular during the last three decades of the $20^{\text {th }}$ century. The proportion of the population with a medium level education rose from about 30 to 45 per cent between 1970 and 1990; and the proportion with a higher level education increased even faster during the same period, from less than eight to over 20 per cent. The fraction of women with a higher level education was marginally higher than that of men, 21.3 compared to 20.7 percent. The labor force participation rates of both genders were high and almost equal. In 1990 it was 86 percent for men and 83 for women. Arguably the highest in the world (Granström 1997). Women are also deeply involved in politics. Following the 1994 elections 41 per 
cent of members of Parliament (Riksdag) were women as were 11 of 22 cabinet members (Chesnais 1996).

All of the above is an expression of a number of long-term progressive social policies and attitudes. Gender equality in Sweden has been affirmed as a basic principle and right longer than in any other country and supported by policy and practical measures since the 1930s. Social arrangements aim to minimize the conflict between childbearing, family responsibilities and career. Parental allowances are generous and apply to both parents. There is a well-established network of child-care facilities, yet at the same time a large proportion of women are working part-time. The family friendly social policies of the Swedish governments were continuously considered an important priority and undoubtedly exerted an influence on fertility levels and trends. For instance, the increase in the total period fertility rate from 1.6 in the early 1980 s to 2.1 in 1990-92 (Fig. S-1) was at least in part due to a financial incentive which was significantly strengthened during the 1980s and favored the close spacing of births (Hoem 1990).

The total cohort fertility rate (TCFR) has been remarkably stable for many generations, i.e. those born since the 1920s. The generations born around 1920 had a TCFR of 2.0 and it appears that that will be the value for the 1960 generation as well. The highest TCFR ever -- 2.16 -- was reached by the birth cohort of 1933-34 (Fig S-1). Given the long history of accurate Swedish population statistics, TCFRs are known for the generations born late in the $19^{\text {th }}$ century. The generations born during the first decade of the $20^{\text {th }}$ century which were at the height of their childbearing during the late 1920s and the 1930s did have TCFRs of around 1.8 children per woman (Fig. S-2).

Even though the trend of total cohort fertility rates was stable, the age patterns of childbearing did differ quite perceptibly from one cohort to the next (Fig. S-2 and S-3). The 1930-31 generation had births spread out quite evenly over the childbearing period with a peak in their mid-twenties. Women of the 1940-41 generation had most of their children earlier; their fertility was higher than that of women 10 years older when they were in their twenties and much lower when in their thirties, 30 to 40 percent lower between the ages of 33 and 37. The subsequent cohorts started a trend of postponing births. The 1950-51 generation had visibly less children at the peak of their childbearing but caught up with the 1940-41 generation when they were in their thirties and early forties. Between the ages of 34 and 43 fertility of the 1950-51 cohort was 40 to 80 percent higher than that of the cohort ten years older. The practice of postponing births was even more pronounced among the cohorts born during the 1950s. The 1960-61 generation had considerably lower fertility, from 30 to 70 percent lower, from ages 15 to 23. The peak years of childbearing shifted into the late 20s and especially from age 28 to age 33 fertility of the $1960-61$ birth cohort was very high compared to any previous generation (Fig. S-3). 
While the life-time patterns of childbearing changed quite considerably between generations, basically the deficits at particular ages were offset by surpluses at other ages (Table S-1). Contrary to many other countries, in Sweden the generations of women born in the 1940s and especially those born in the 1950s who decided to have their children later in life actually did so.

Table S-1: $\quad$ Fertility deficits and surpluses comparing birth cohorts, Sweden, cohorts 1930-31, 1940-41, 1950-51 and 1960-61

\begin{tabular}{|c|c|c|c|c|c|c|}
\hline \multirow[t]{2}{*}{ Fertility } & \multicolumn{2}{|c|}{$\begin{array}{l}\text { Cohort 1930-31 and } \\
1940-41\end{array}$} & \multicolumn{2}{|c|}{$\begin{array}{l}\text { Cohort 1940-41 and } \\
1950-51\end{array}$} & \multicolumn{2}{|c|}{$\begin{array}{l}\text { Cohort 1950-51 and } \\
1960-61\end{array}$} \\
\hline & $\begin{array}{l}\text { Age } \\
\text { group }\end{array}$ & $\begin{array}{l}\text { Number of } \\
\text { children }\end{array}$ & $\begin{array}{l}\text { Age } \\
\text { group }\end{array}$ & $\begin{array}{l}\text { Number of } \\
\text { children }\end{array}$ & $\begin{array}{l}\text { Age } \\
\text { group }\end{array}$ & $\begin{array}{l}\text { Number of } \\
\text { children }\end{array}$ \\
\hline \multirow[t]{3}{*}{ Deficit } & $19-20$ & -0.004 & $18-28$ & -0.186 & $15-25$ & -0.270 \\
\hline & $27-42$ & -0.192 & & & $39-49^{a}$ & -0.004 \\
\hline & $46-49$ & -0.000 & & & & \\
\hline \multirow[t]{3}{*}{ Surplus } & $15-18$ & +0.011 & $15-17$ & +0.021 & $26-38$ & +0.272 \\
\hline & $21-26$ & +0.088 & $29-49$ & +0.146 & & \\
\hline & $43-45$ & +0.001 & & & & \\
\hline Total & & -0.096 & & -0.030 & & +0.017 \\
\hline
\end{tabular}

Women of the 1950-51 birth cohort had 0.186 children less than women 10 years older when they were young, i.e. between the ages of 18 and 28 . After age 29, however, they had 0.146 children more than the 10 years older generation. They did not catch up altogether but their completed cohort fertility rate was only 1.5 percent smaller than that of the 1940-41 generation, a difference of 0.03 children. The 1960-61 birth cohort even had a small net fertility surplus of 0.017 children.

Note the big dip in the curve for the cumulated difference between the 1960-61 curve and the base line for the 1950-51 cohort at the trough of the curve at age 26 in Fig. S-4. The difference was almost minus 0.3 children. More precisely, it was -0.270 (Table S-1). As, however, this cohort experienced a fertility surplus of +0.272 between the ages of 26 to 38 compared to the 1950-51 cohort the net difference was +0.017 children. The TCFR was 0.9 per cent larger than that of the 1950-51 generation even though at specific individual ages the fertility difference was 50 to 60 per cent smaller or larger, respectively. The 1960-61 curve of cumulated fertility differences crosses the 1950-51 base line in Fig. S-4 around age 34 and then stays above that line.

What is extremely difficult to predict is the future childbearing behavior of those cohorts that were at the beginning or in the middle of their fertile period in the late 1990s. There are certain signs that point to probable trends which can be deduced from 
the information in Table S-2 and Figs. S-4 and S-5. The cohorts born in the mid-1960s, represented here by the 1965-66 birth cohort, display a trend comparable to that of the 1960-61 generation. The shape of the curve for this generation is quite similar to that of the 1960-61 cohort, but the postponement of births prior to age 25 is even more pronounced, however -- as far as the curve goes -- once the 1965-66 generation reaches its late twenties, the catching up inclination weakens.

By definition, the available data for the younger cohorts born in the late 1960s and early 1970s are for even shorter periods of the childbearing experience. So far these data show that the postponement of births of these generations is very strong (Fig. S-4 and S-5 and Table S-2). It is impossible to say how forceful the catching up will be when these generations will be older. It is clear that the large deficits that will be accumulated by these generations during their teens and twenties will require inordinately large surpluses if they were to come anywhere close to replacement level fertility. In other words, it now appears likely that the generations born in Sweden in the late 1960s and early 1970s will be the first ones after a long time to have significantly below replacement fertility.

Table S-2: $\quad$ Cumulated fertility rates at specified ages and relative changes compared to birth cohorts 10 years older, Sweden, cohorts 1960-61, 1965-66, 197071 and 1975-76.

\begin{tabular}{lllllllll}
\hline \multirow{2}{*}{ Age } & \multicolumn{3}{c}{ Cumulated fertility rate of birth cohort } & \multicolumn{3}{l}{$\begin{array}{l}\text { Change of CCFR compared to cohort } \\
\text { ten years older (in per cent) }\end{array}$} \\
\cline { 2 - 10 } & $1960-$ & 1965 & $1970-$ & $1975-$ & $1960-$ & $1965-$ & $1970-$ & $1975-$ \\
& 1961 & $19-66$ & 1971 & 1976 & 1961 & 1966 & 1971 & 1976 \\
\hline 36 & 1.900 & n.a. & n.a. & n.a. & +1 & n.a. & n.a. & n.a. \\
31 & 1,519 & 1.443 & n.a. & n.a. & -4 & -5 & n.a. & n.a. \\
26 & 0.793 & 0.805 & 0.665 & n.a. & -25 & -12 & -16 & n.a. \\
21 & 0.220 & 0.170 & 0.189 & 0.118 & -43 & -48 & -14 & -31 \\
\hline
\end{tabular}


Figure S-1: Total period fertility rate, Sweden, 1950-2000, and total cohort fertility rate in Swedish birth cohorts, 1918-1966 lagged by the average age at childbearing

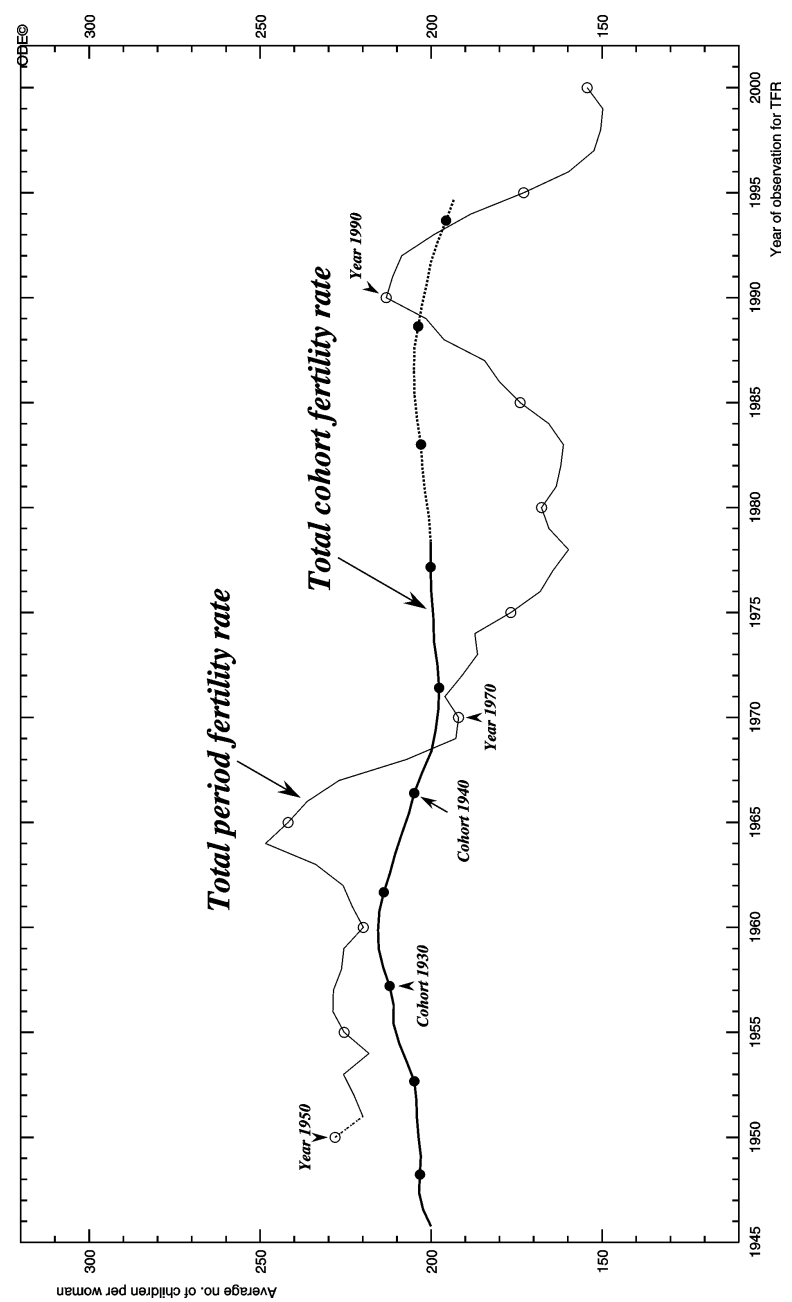

Note: Dotted lines indicate that a minor proportion of the respective TCFRs is based on estimates 
Figure S-2: $\quad$ Cumulated cohort fertility at specified ages, Sweden, birth cohorts 19221975

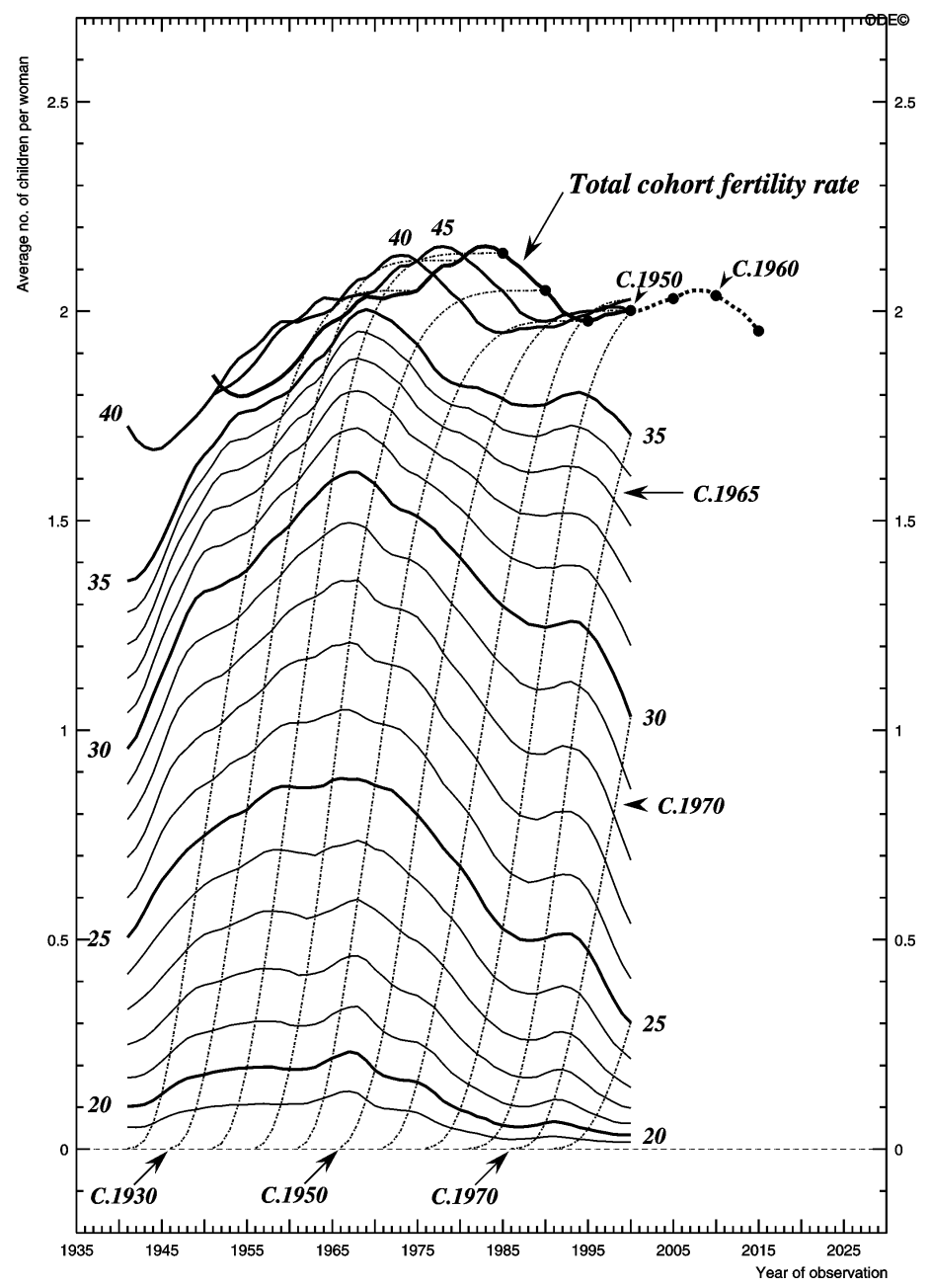

Note: The part of the TCFR line which is dotted indicates that a minor proportion of the TCFR is based on estimates 
Demographic Research - Volume 5, Article 5

Figure S-3: Age-specific fertility rates, Sweden, birth cohorts 1930-31, 1940-41, 1950-51 and 1960-61

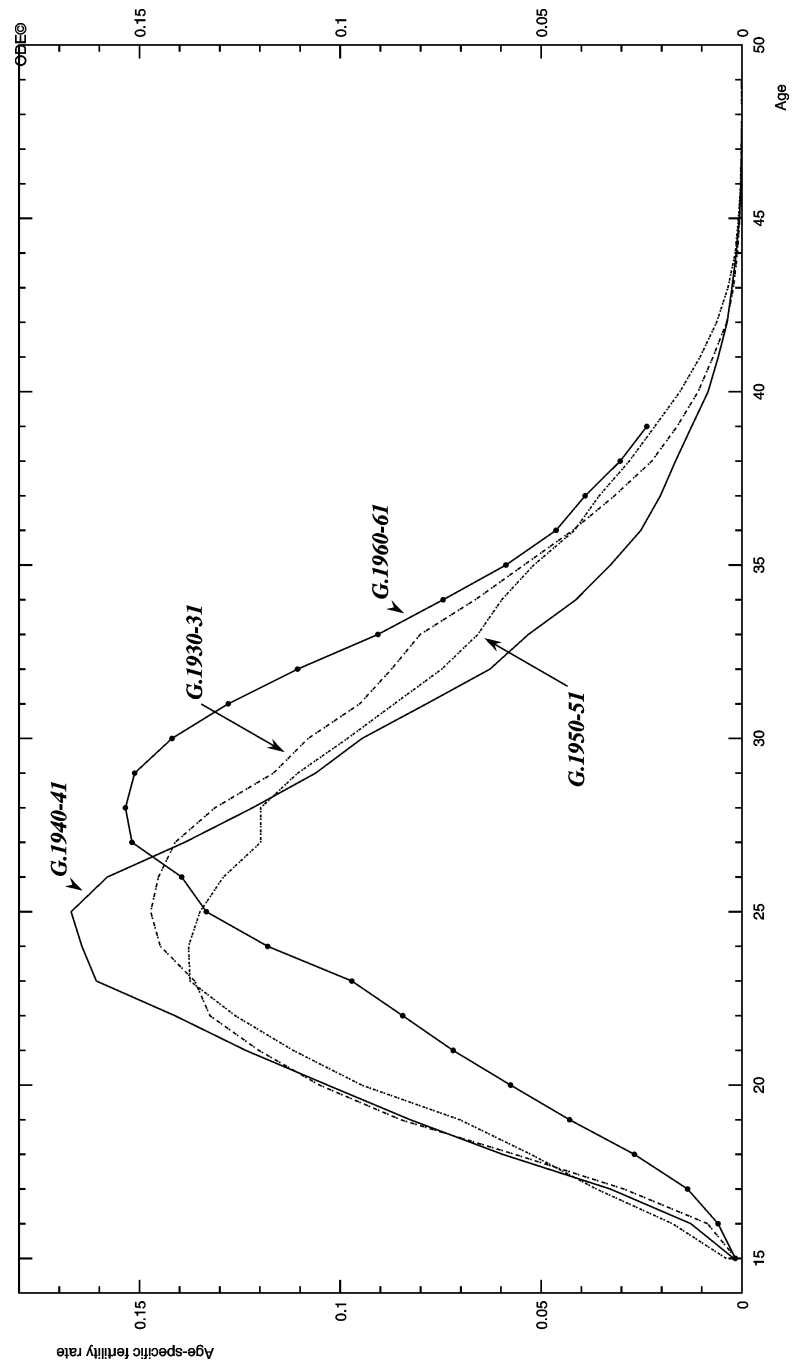


Demographic Research - Volume 5, Article 5

Figure S-4: Differences in cumulative age-specific cohort fertility rates between base and subsequent cohorts: Sweden, women born in 1950-51 (base), 195556, 1960-61, 1965-66, 1970-71 and 1975-76

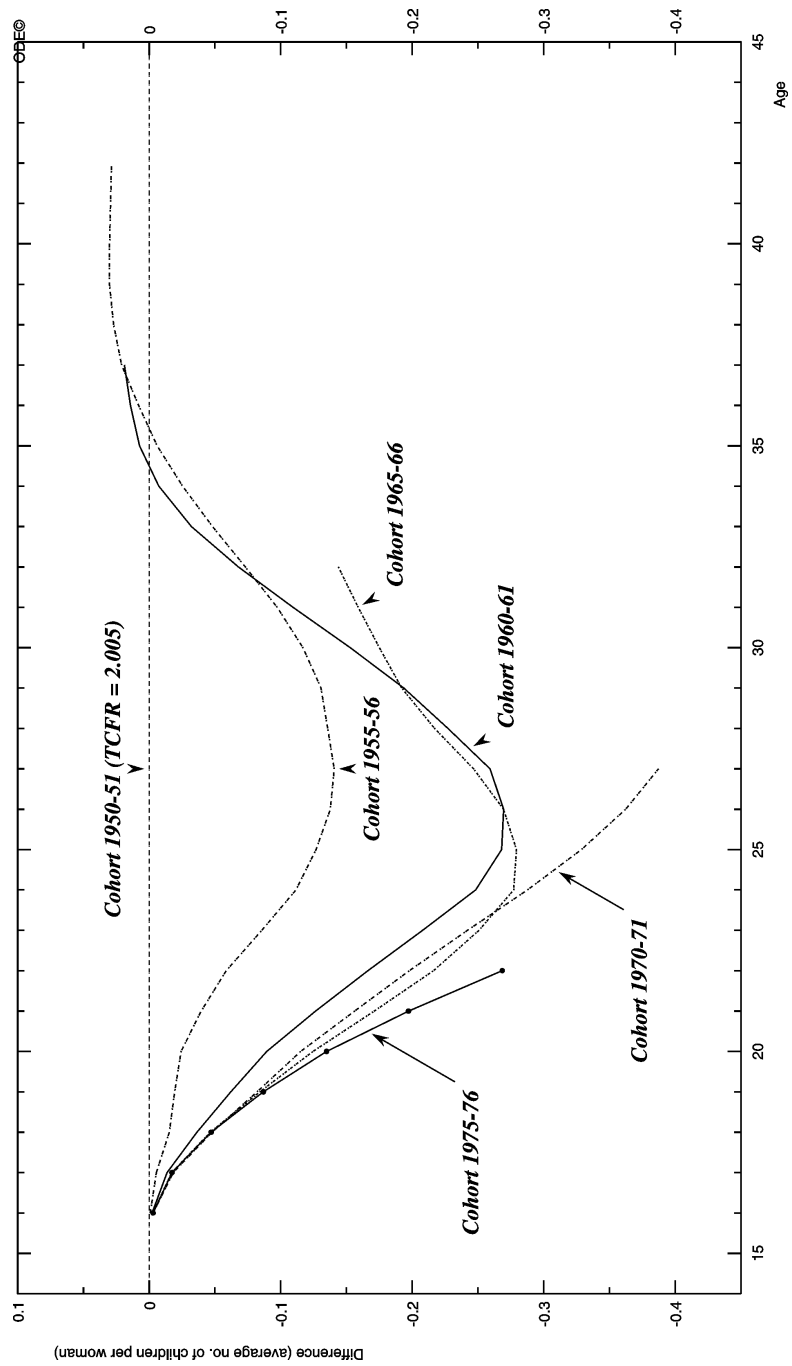


Figure S-5: Age-specific fertility rates, Sweden, birth cohorts 1960-61, 1965-66, 1970-71 and 1975-76

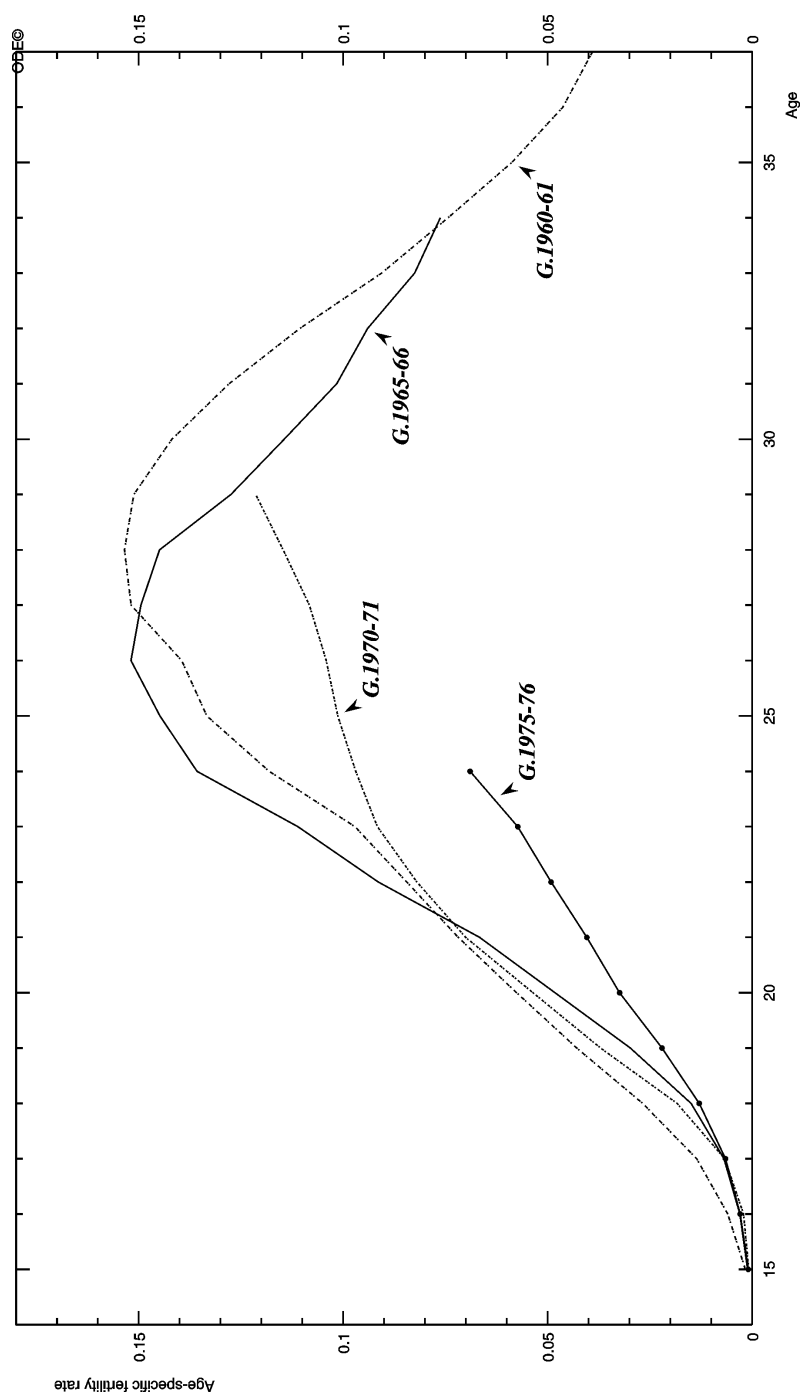

